\title{
Testing of Passive Energy Dissipation Systems
}

\section{Ian D. Aiken, Douglas K. Nims, Andrew S. Whittaker, and James M. Kelly}

\begin{abstract}
Over the period 1986 to 1991 , seven different passive energy dissipation systems were studied in experimental research programs at the Earthquake Engineering Research Center of the University of California at Berkeley. This paper presents an overview of these studies, describing the different types of devices, the results of the shake table experiments, and associated analytical work. Four of the systems studied are friction systems, and of these, three (Sumitomo, Pall, and Friction-Slip) are based on Coulomb friction. The fourth is the FluorDaniel Energy Dissipating Restraint, which is a device capable of providing selfcentering friction resistance that is proportional to displacement. The three other systems all have different energy dissipation mechanisms: ADAS elements, which utilize the yielding of mild-steel X-plates; viscoelastic shear dampers using a $3 \mathrm{M}$ acrylic copolymer as the dissipative element; and Nickel-Titanium alloy shapememory devices that take advantage of reversible, stress-induced phase changes in the alloy to dissipate energy. The effectiveness of the various systems is evaluated by comparing the response of the test structures without and with the energy dissipators. In some cases, where devices were studied using the same test structure, they are compared directly. All of the systems investigated exhibited characteristics beneficial to improved structural response to earthquake loading.
\end{abstract}

\section{INTRODUCTION}

Conventional seismic design practice permits the reduction of forces for design below the elastic level on the premise that inelastic action in a suitably designed structure will provide that structure with significant energy dissipation potential and enable it to survive a severe earthquake without collapse. This inelastic action is typically intended to occur in specially detailed critical regions of the structure, usually in the beams near or adjacent to the beam-column joints. Inelastic behavior in these regions, while able to dissipate substantial energy, also often results in significant damage to the structural member, and although the regions may be well detailed, their hysteretic behavior will degrade with repeated inelastic cycling. The interstory drifts required to achieve significant hysteretic energy dissipation in critical regions are generally large and usually result in substantial damage to non-structural elements such as in-fill walls, partitions, doorways, and ceilings.

As a response to the shortcomings inherent in the philosophy of conventional seismic design, a number of innovative approaches have been developed. One of these approaches involves adding energy absorbers to a structure. The aim of including energy absorbers in a structure for earthquake resistance is to concentrate hysteretic behavior in specially designed and detailed regions of the

(IDA, ASW, and JMK) EERC, University of California at Berkeley, Berkeley, CA 94720

(DKN) Department of Civil Engineering, University of Toledo, Toledo, OH 43606 
structure and to avoid inelastic behavior in primary gravity load- resisting structural elements (except perhaps under the most severe conditions).

Numerous different types of energy-absorbing devices have been proposed for this purpose. Devices based on the plastic deformation of mild steel were developed and extensively tested a number of years ago (Kelly, 1972). Friction devices of several types have been the subject of a number of research programs, and there are now a number of building applications. The Pall-type friction damper has been used in three buildings in Canada, in two new buildings, and in the retrofit of a school building damaged in the Saugenay earthquake of 1989 (Pall, 1987 and 1991, Vezina, 1992). By the middle of 1991, Sumitomo-type friction dampers had been incorporated in 31- and 22-story buildings, both in Japan. Lead extrusion dampers were used in a recently completed 17story building, and also in an 8-story building, both in Japan. The first U.S. application of ADAS elements for the seismic retrofitting of a building was completed in San Francisco in early 1992 (Fierro, 1993). Viscoelastic dampers have been used in several tall buildings for wind vibration control. The dampers use a highly dissipative polymeric material which has well-defined material properties and behavioral characteristics (Mahmoodi, 1969). The most notable applications are the twin 110-story towers of the World Trade Center in New York City, where dampers have been installed for 20 years (Mahmoodi, 1987). Several other high-rise buildings in the U.S. also use viscoelastic dampers for wind vibration control (Keel, 1986, Mahmoodi, 1989). In Tokyo, a 24story building was recently completed with bituminous-rubber viscoelastic dampers, providing the structure with increased damping to resist earthquake loadings (Yokota, 1992).

The role of a passive energy dissipator is to increase the hysteretic damping in the structure. The basic energy relationship of the structure is represented in the following equation:

$$
E_{I}=E_{K}+E_{S}+E_{\xi}+E_{H}
$$

where:

$E_{I}=$ earthquake input energy

$E_{K}=$ kinetic energy in structure

$E_{S}=$ strain energy in structure

$E_{\xi}=$ viscous damping energy

$E_{H}=$ hysteretic damping energy

The role of this equation in the design process has been developed by a number of researchers (Uang, 1988, Filiatrault, 1990a). The goal is to increase $E_{H}$ so that, for a given $E_{I}$, the elastic strain energy in the structure is minimized. This means that the structure will undergo smaller deformations for a given level of input energy than if it did not include energy dissipators. Alternately, increasing $E_{H}$ permits $E_{S}$ to be reduced for a higher level of $E_{I}$. 


\section{LARGE-SCALE EARTHQUAKE SIMULATOR STUDIES}

\section{SUMITOMO FRICTION AND 3M VISCOELASTIC DAMPERS}

This section presents a summary of the results of the tests of the Sumitomo friction damper and the $3 \mathrm{M}$ viscoelastic shear damper. Both series of tests were performed using the same largescale 9-story steel frame. More details of the results of these shake table tests are given by Aiken (1990a and 1990b).

\section{DESCRIPTION OF TEST FACILITY AND MODEL STRUCTURE}

The experimental program was carried out using the earthquake simulator at the Earthquake Engineering Research Center of the University of California at Berkeley. The earthquake simulator

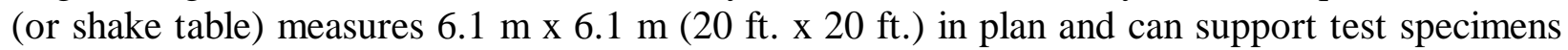
weighing up to $580 \mathrm{kN}$ (130 kips). Simulated seismic motions can be applied vertically and in one horizontal direction, with maximum accelerations of $1.0 \mathrm{~g}$ and $1.5 \mathrm{~g}$, respectively.

The basic test structure was a 9-story, moment-resisting steel frame representing a section of a typical steel building at $1 / 4$-scale. The structure was tested as a moment-resisting frame (MRF), a concentrically-braced frame (CBF), and in friction-damped (FD) and viscoelastically-damped (VD) configurations (Fig. 1). The VE dampers were added to the MRF in single-diagonal bracing (Fig. 2), and the friction dampers were added as part of a modified chevron bracing system (Fig. 3).

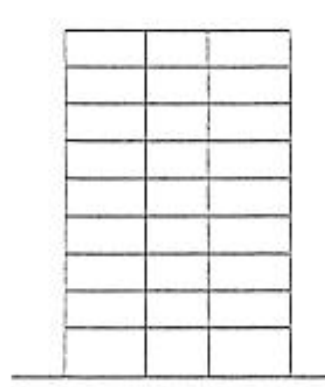

(a) MFF

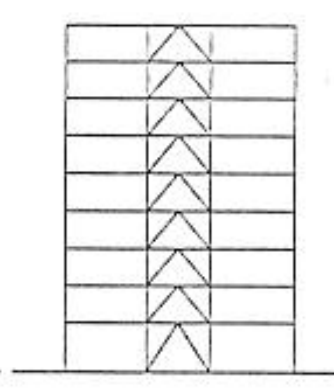

(b) CBF

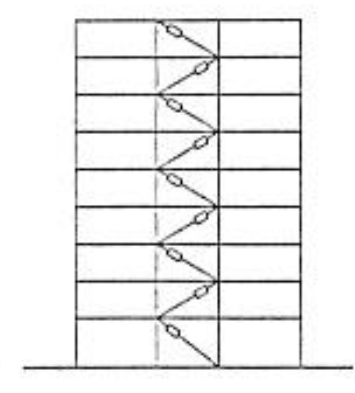

(c) VD

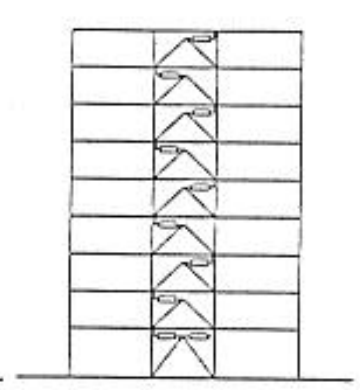

(d) FD

Fig. 1: Test Configurations of Model Structure

Mass-similitude scaling, such that model and prototype accelerations are equal, was used for the shake table tests. This required that approximately $400 \mathrm{kN}$ (90 kips) of mass be added to the model in the form of concrete blocks and lead billets. The total test weight of the model was 445 $\mathrm{kN}$ (100 kips). Response quantities measured during the shake table tests included floor 
displacements and accelerations, brace axial forces and damper displacements, base shear and base overturning moment, and shake table accelerations and displacements.

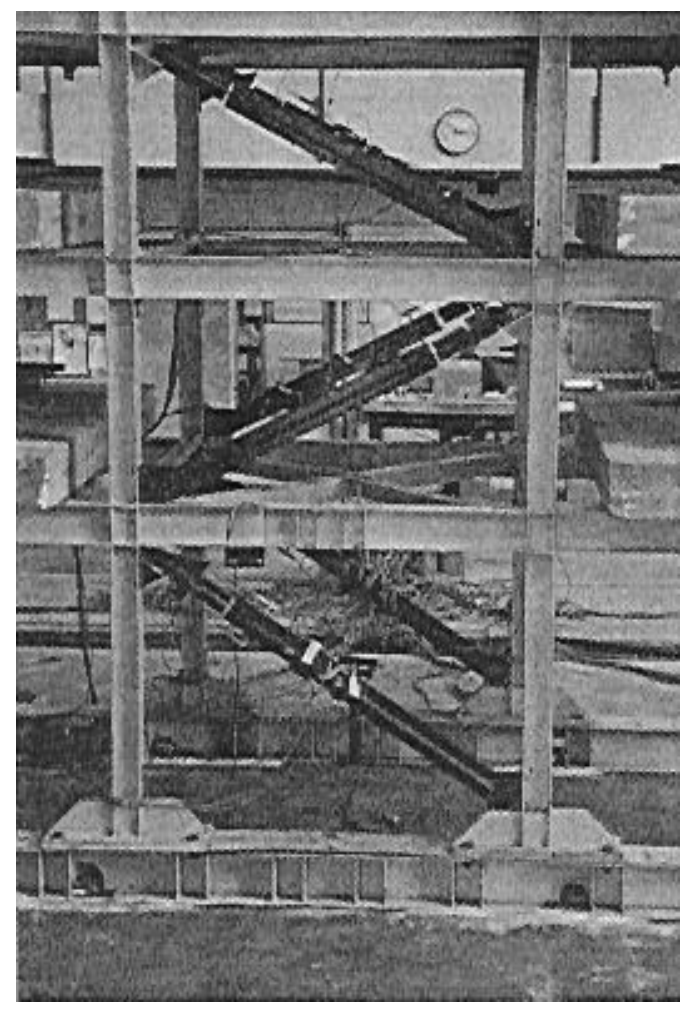

Fig. 2: View of Bottom Three Levels of Model With Viscoelastic Dampers

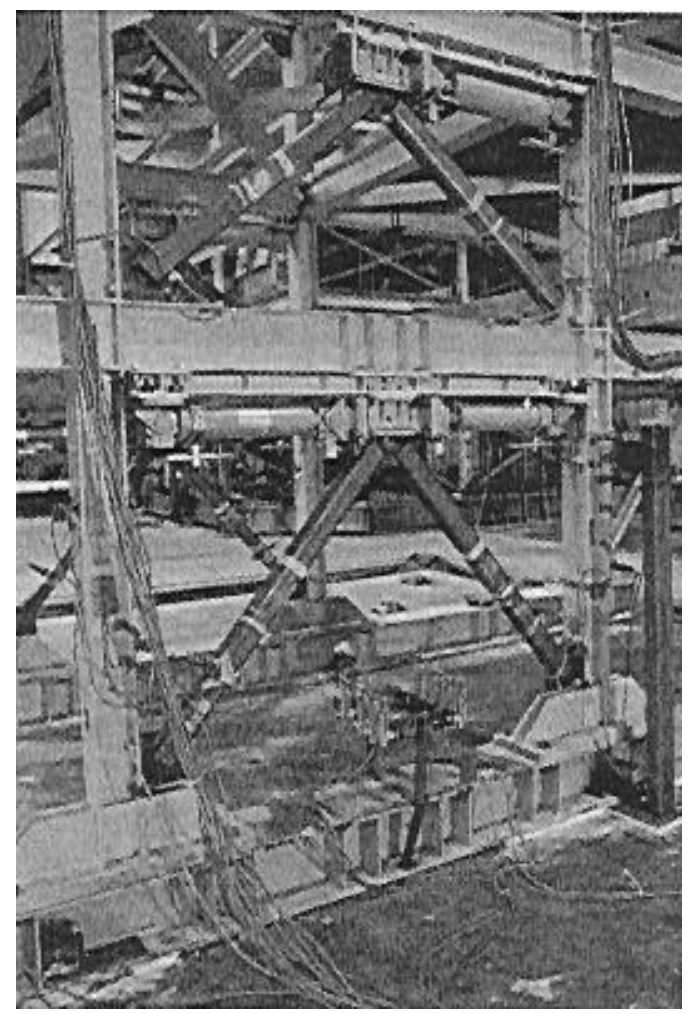

Fig. 3: View of Bottom Three Levels of Model With Friction Damper

\section{DESCRIPTION OF DAMPERS}

The two types of devices studied were a viscoelastic (VE) shear damper and a sliding friction damper. The VE damper comprises two layers of material (Fig. 4), and was introduced in singlediagonal bracing in the test structure (Fig. 5). The VE material used in the dampers is an acrylic copolymer developed by $3 \mathrm{M}$ Co. It is one of four types of highly dissipative polymer currently available from 3M. The VE material behavior is influenced by its shear loss modulus, the shear storage modulus, and their ratio, the material loss factor (Mahmoodi, 1969). These properties are dependent on frequency, temperature, and deformation strain level, and the general relationship is the same for all of the materials. Thus, one general relationship can be used to predict the properties for any of the four materials. This is the basis of material property charts developed by the manufacturer.

The friction damper was designed and developed by Sumitomo Metal Industries, Ltd., Japan. It is a cylindrical device with friction pads that slide directly on the inner surface of the steel casing of the device (Fig. 6). The friction devices were attached to the underside of the floor beams and connected to chevron brace assemblages (Fig. 7). The device was originally developed as a shock absorber in railway rolling stock. The mechanical characteristics of both types of dampers were 
well-known from previous studies, and both have already been used in a number of structural or mechanical engineering applications. This experimental study represented the first system-level test of the dampers for severe earthquake loading conditions..

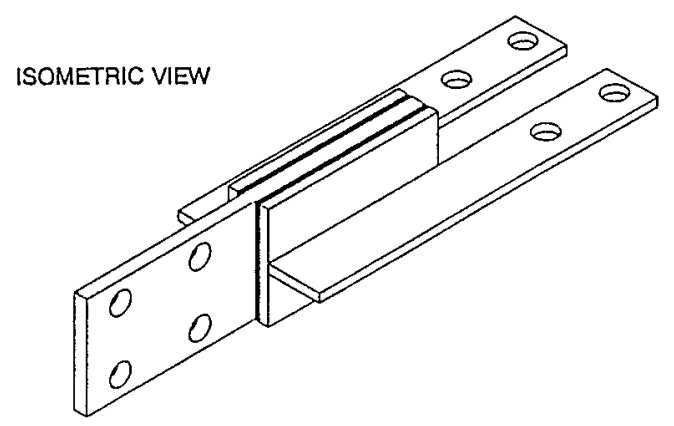

Fig. 4: VE Constrained Layer Shear Damper

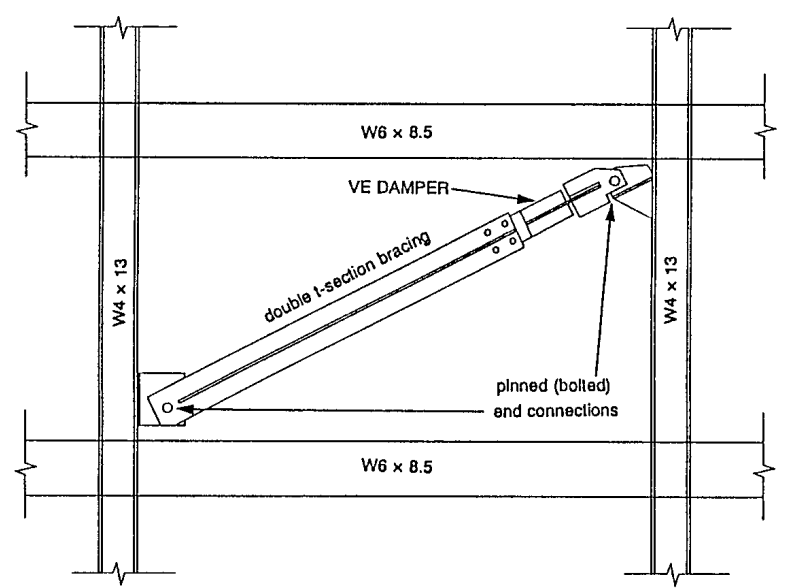

Fig. 5: Installation of VE Dampers in Model

\section{DESIGN OF DAMPING SYSTEMS}

\section{Friction Dampers}

The size (slip force) of the friction dampers and their layout in the test structure was determined using a nonlinear time-history analysis approach. An initial slip load distribution was chosen based on the results of a previous shake table study of the test structure, utilizing another type of friction damper (Aiken, 1988), and a series of analyses were performed for a number of different earthquake records at various input levels. The final slip load distribution was chosen as 
that which provided the lowest structural response for all of the inputs. The slip loads varied from 11.5 kips at the bottom level to 4.8 kips at the top level of the test structure..
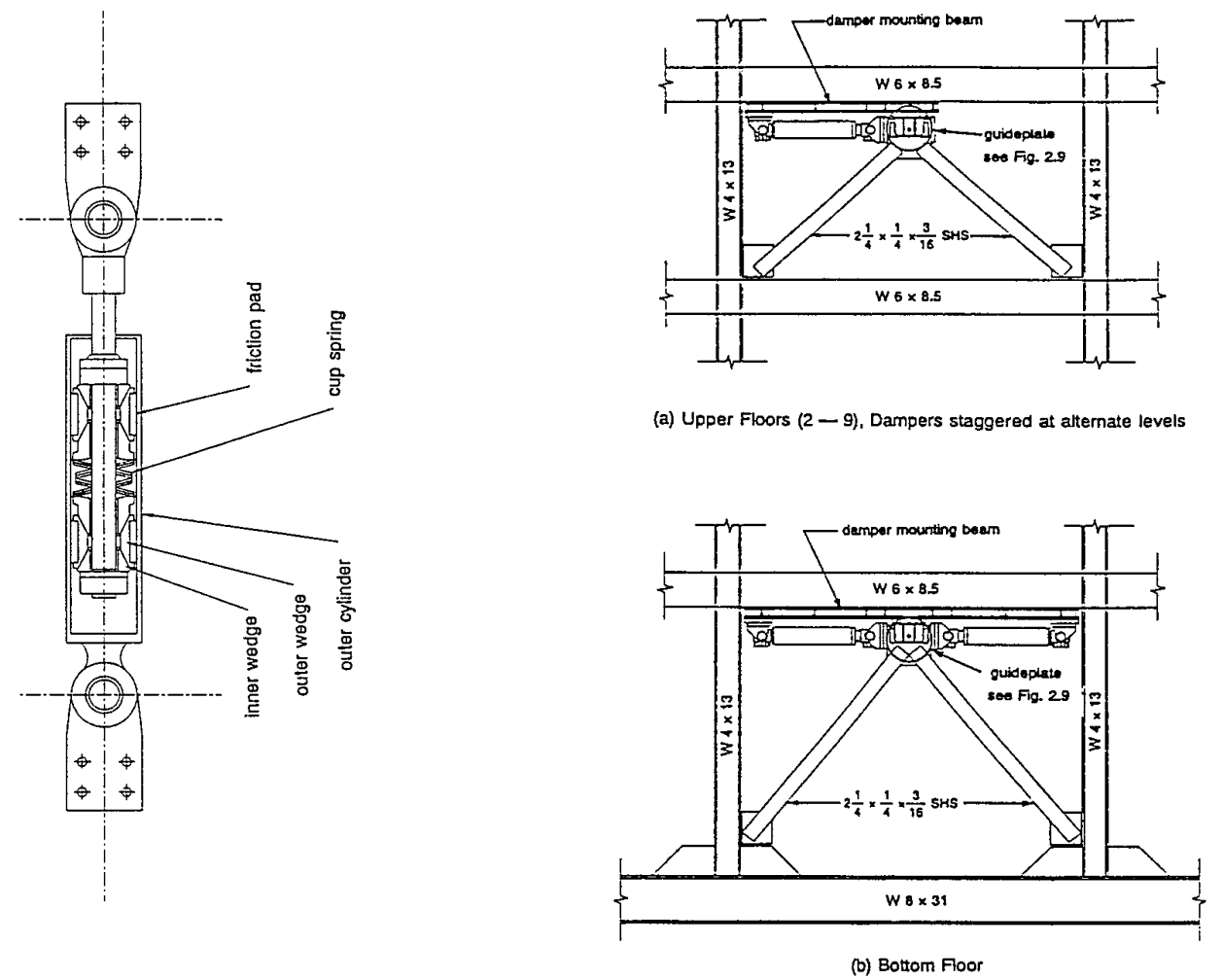

Fig. 6: Sectional View of Friction Damper

Fig. 7: Friction Dampers Installed in Model

\section{$\underline{\text { Viscoelastic Dampers }}$}

The method used for the design of the VE dampers for the test structure was a simplified firstmode procedure aimed at providing the structure with a specified level of damping (10 percent) at a nominal maximum displacement. This was done using an energy approach. A complete description of the procedure used is given by Aiken (1990). The VE dampers consisted of two 3" x $5 "$ x $0.15 "$ layers of VE material.

\section{EARTHQUAKE SIMULATOR STUDY}

\section{Description of Experiments}

The four configurations of the model structure (Fig. 1) were subjected to a number of different dynamic tests. These were pull-back free vibration, pulse, random noise, and earthquake tests. Fundamental frequencies for the MRF and CBF of $1.95 \mathrm{~Hz}$ and $2.95 \mathrm{~Hz}$, respectively, were identified. The dynamic characteristics of the VD and FD models were a function of the level and type of excitation, and were largely a result of whether or not the dampers were activated during the motion. From the results of the pulse tests, the fundamental frequencies of the VD (dampers 
activated) and the FD (dampers not activated) models were $2.30 \mathrm{~Hz}$ and $2.60 \mathrm{~Hz}$, respectively. The remaining discussion of results is devoted to those from some of the earthquake tests.

Fourteen different earthquake motions were used in the shake table tests of the MRF, CBF, FD, and VD structures. Results are discussed for some of the results obtained for the following earthquake ground motions:

(i) El Centro, Imperial Valley, California, May 18, 1940,

(ii) Miyagi-ken-oki, Tohoku University, Sendai, Japan, June 12, 1978,

(iii) Taft, Kern County, California, July 21, 1952,

(iv) Llolleo, Chile, March 3, 1985,

(v) La Union (Guerrero array), Michoacan, Mexico, September 19, 1985.

$\underline{\text { Results }}$

Hysteresis Behaviors: Typical hysteresis loops for the two types of dampers are shown in Fig. 8. The VE dampers exhibit elliptical hysteresis loops typical of materials with velocitydependent properties. The loops are regular in shape and show stable behavior.

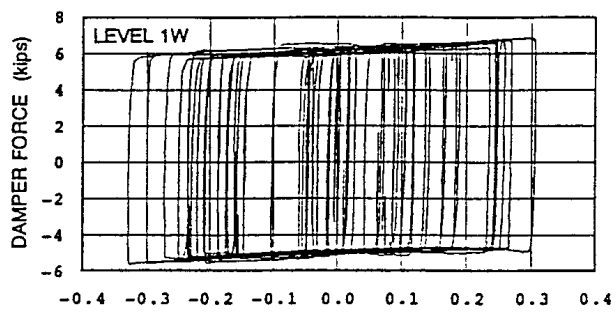

(a) Friction Damper - Chile-750 Test

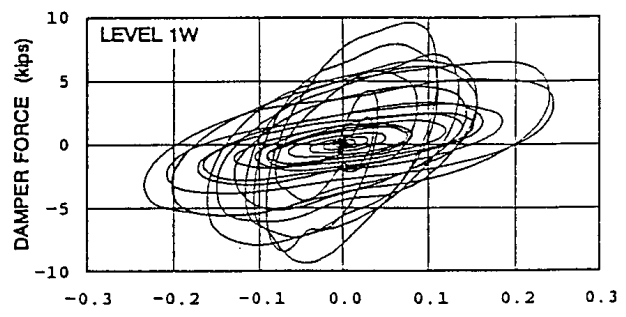

(b) VE Damper - Miyagi-300 Test

Fig. 8: Typical Damper Hysteresis Loops

A maximum VE damper shear strain of 208 percent was obtained throughout the VD model tests. Viscoelastic dampers have no threshold or activation force level, and thus they dissipate energy for all levels of earthquake excitation. This contrasts with the behavior of the friction dampers, which, for forces less than the slip force, do not slip and thus do not dissipate energy. The stiffness characteristics of the VE dampers are dependent on a number of factors, notably strain amplitude, frequency, and temperature. The variation of VE damper stiffness with shear strain for all of the Miyagi tests is shown in Fig. 9. Between strains of about 0 and 50 percent, there is a large decrease in stiffness, but for strains in the range of about 50 to 200 percent, the stiffness can be regarded as approximately constant. This assumption was utilized to determine the "effective" damper stiffnesses for the numerical analyses described below. Temperature increases in the VE material during earthquake shaking were small and did not significantly affect the behavior of the VE dampers. 


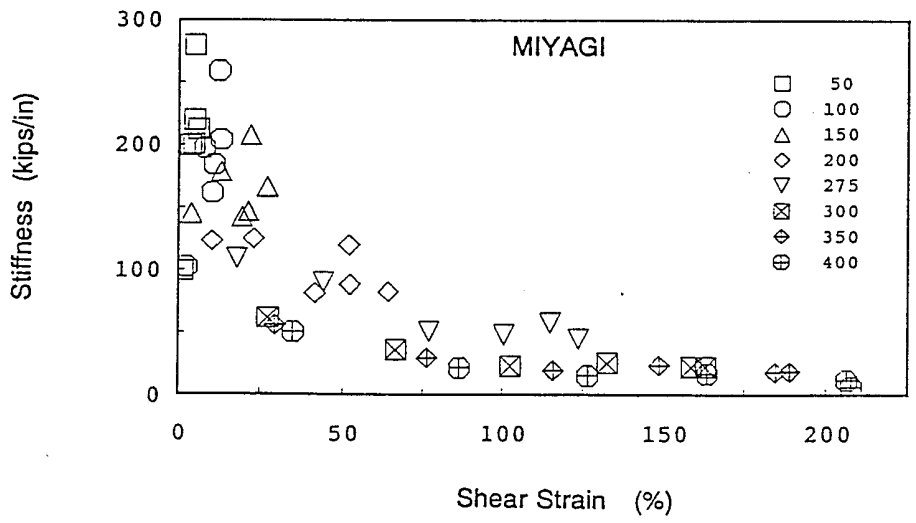

Fig. 9: VE Damper Stiffness vs. Shear Strain for Miyagi Tests

The friction dampers exhibited outstanding behavior. Their hysteretic behavior is extremely regular and repeatable. The devices showed almost no variation in slip load during earthquake motions, and from previous tests of individual dampers, their force-displacement response was known to be basically independent of loading frequency, amplitude, number of loading cycles, and temperature. In contrast to the VE dampers, the friction dampers are not activated during small excitations. Under such circumstances, the FD model behaved more as though it were a CBF.

Because of the variation in VE damper stiffness with strain amplitude, the fundamental frequency of the VD structure varied with excitation level from $2.43 \mathrm{~Hz}$ down to $2.00 \mathrm{~Hz}$, compared with $1.95 \mathrm{~Hz}$ for the MRF. Low-level earthquake tests of the FD model revealed a fundamental frequency of $2.67 \mathrm{~Hz}$ (compared with $2.95 \mathrm{~Hz}$ for the $\mathrm{CBF}$ ), while for large excitations, a variation of 2.47 to $2.35 \mathrm{~Hz}$ was observed.

System Comparisons: Shake table response comparisons of the various systems were made wherever possible. For a sequence of El Centro and Miyagi tests, the VD model generally behaved in the same way as the CBF with regard to displacements and in the same way as the MRF with regard to accelerations. The same general trends were also seen for the FD model compared with the CBF and MRF models. Peak base shears of the FD, VD, and MRF models for a series of Miyagi tests are compared in Fig. 10, where the FD and VD shears are seen to be less than that of the MRF. This, coupled with the reduced drifts due to the presence of the dampers, represents a significant overall improvement in response. A large number of equivalent tests were performed on the MRF, FD, and VD models. From response comparisons for the El Centro, Taft, and Miyagi sequences of inputs, drifts in both the FD and VD models were reduced by 10 to 60 percent over those of the MRF, while story accelerations were reduced by 25 to 60 percent. In all cases, the FD and VD responses were reduced from those of the MRF.

Floor response spectra were also used to compare the MRF, FD, and VD models. Two percent-damped spectra for the third floor of each of the models are presented in Fig. 11 for the Miyagi-400 tests. The damped structures both show significant reductions in spectral acceleration, particularly over the range of 5 to $10 \mathrm{~Hz}$. Above $10 \mathrm{~Hz}$, the VD spectrum is about half that of the 
MRF, while the FD spectrum is less than or about the same as that of the MRF. These results, and those for many other earthquake inputs, indicate that these two types of energy absorbers should not pose problems for internal equipment in structures and in the cases studied actually provided improvements over the equivalent MRF.

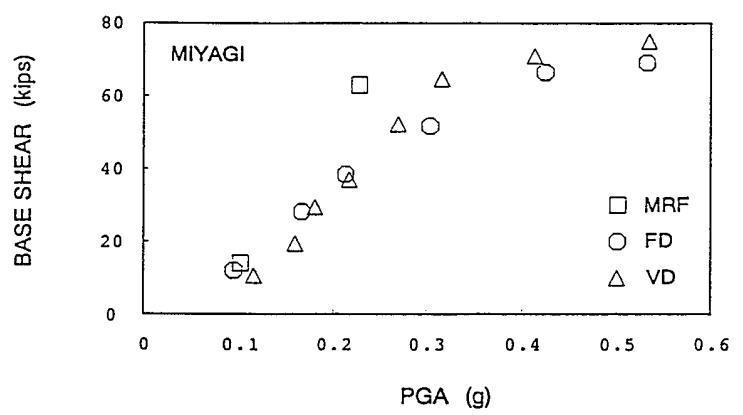

Fig. 10: MRF, FD, and VD Peak Base Shear vs. PGA for Miyagi Tests

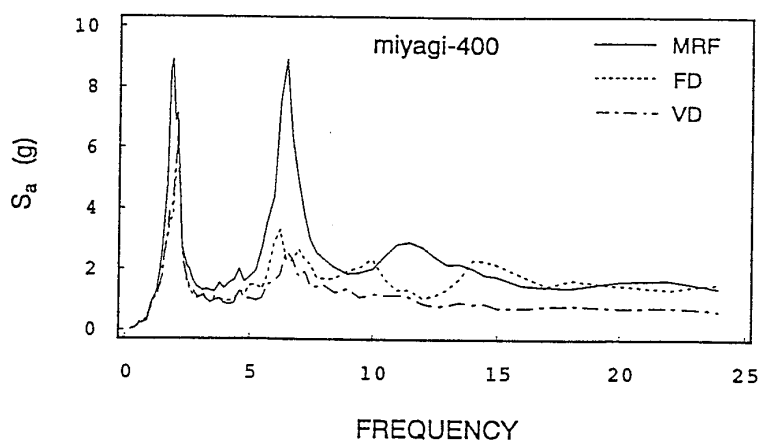

Fig. 11: MRF, FD, and VD Level 3 Two-Percent Damped Floor Response Spectra, Miyagi-400 Tests

Analyses: The FD model was analyzed using the nonlinear analysis program DRAIN-2D. Good agreement with experimental results was obtained. Fig. 12 shows MRF and CBF analysis results for the Chile-750 input. In contrast with these results, there was no yielding in the FD structure under this or any other input used in the test program. The VD model also experienced no yielding in any of the earthquake tests. The stable hysteretic behavior of the friction devices makes them particularly amenable to accurate modeling. A linear elastic analysis approach was used for the VD model, using the finite element program SAP90. The analyses captured both the damping and stiffness characteristics of the VE dampers accurately. Very good correlation results were obtained (Fig. 13). These analyses permitted the separate effects of damping and stiffness to 
be determined (Fig. 14). Increased damping was found to be the major factor in improving the response of the VD model.

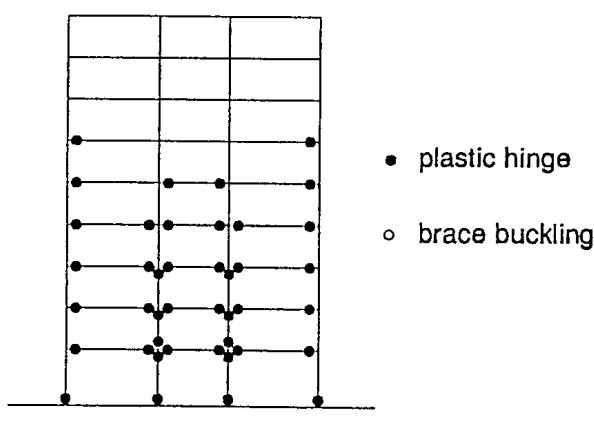

(a) MRF

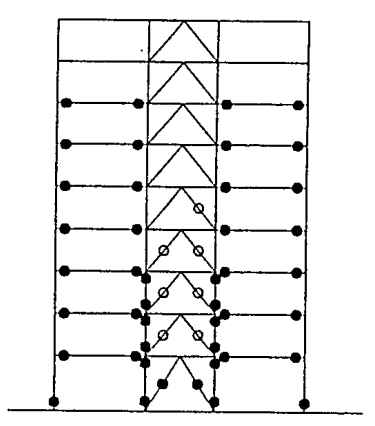

(b) $\mathrm{CBF}$

Fig. 12: Analytical Inelastic Demands, Chile-750 Input

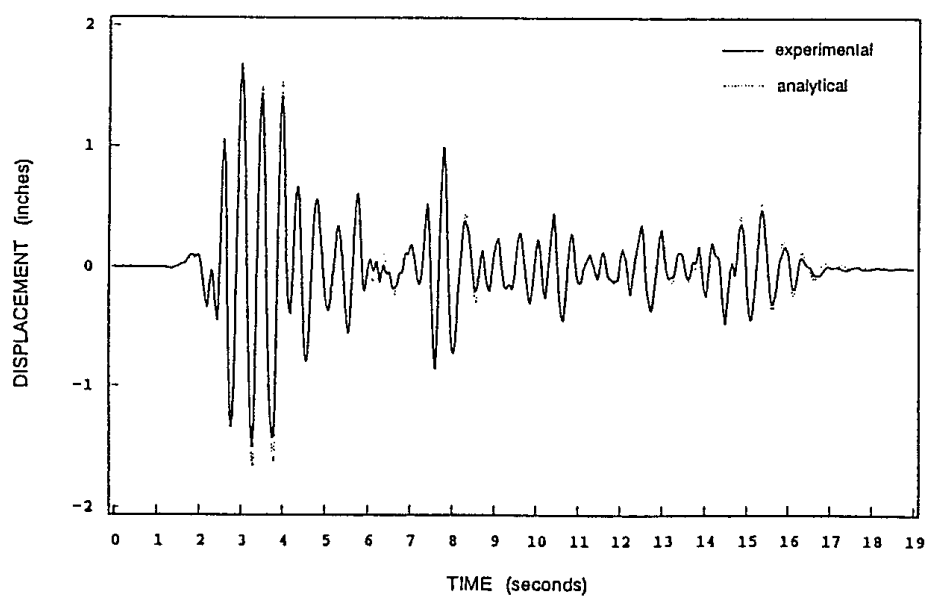

Fig. 13: VD Experimental and Analytical Roof Time Histories, El Centro-250 Input

\section{SUMMARY}

Separate comparisons of the FD and VD systems with the "undamped" MRF and CBF structures showed that both damped systems behaved similarly to the CBF in terms of story drifts and similarly to the MRF in terms of story accelerations and story shears. The FD and VD systems were remarkably similar with regard to acceleration and displacement responses for a wide selection of earthquake inputs. Peak base shears of the FD and VD models were similar for a range of input levels of the El Centro, Miyagi, and Taft signals. They were approximately the same as, or less than, the MRF maximum base shears. These results were achieved while simultaneously reducing the drifts to as little as one-half of those of the MRF.

Floor response spectra showed spectral accelerations of both damped systems to be less than those of the MRF. Neither type of energy absorber caused undesirable high frequency response 
amplifications in the frequency ranges important for internal equipment or nonstructural components.

This combined experimental and analytical study demonstrated the structural response improvements possible through the use of viscoelastic and friction energy absorbers. Existing analysis programs were used to model the structures equipped with energy absorbers with good results. Other studies of VD structures (Lin, 1988; Zhang, 1989) have developed a modal analysis technique which accurately predicts the response of the damped system and provides a practical method for design.

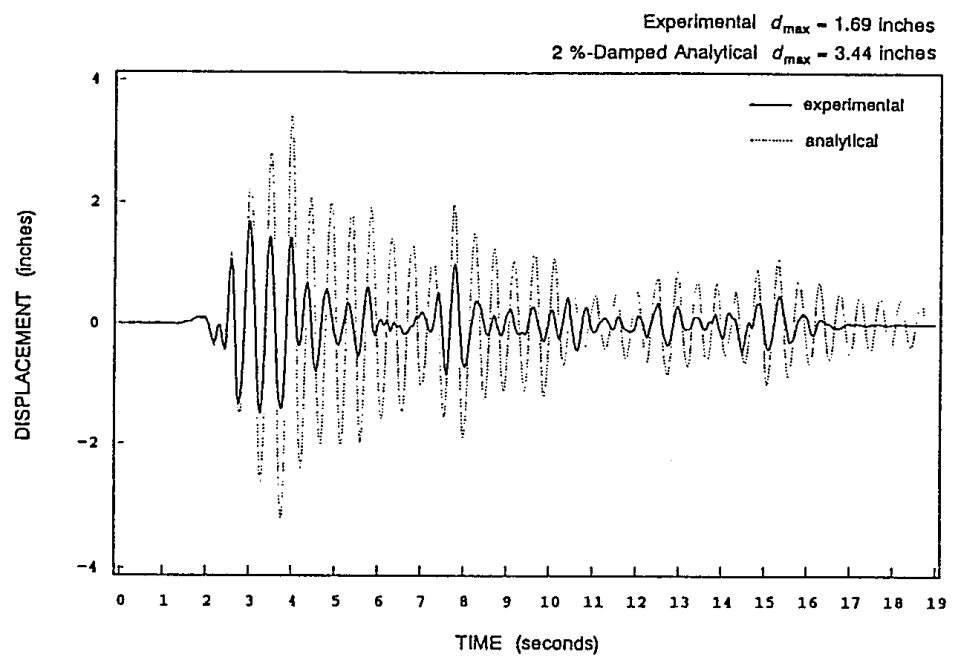

Fig. 14: VD Experimental and Two-Percent Damped Analytical Roof Time Histories, El Centro250 Input

\section{PALL FRICTION DEVICE}

A third experimental study, using the same 9-story steel MRF, investigated the effectiveness of another type of friction device, that developed by Pall (1982).

\section{DESCRIPTION OF DEVICE}

The details of the friction damper are shown in Fig. 15. It consists of diagonal brace elements with a friction interface at their intersection point, which are connected together by horizontal and vertical link elements. These link arms ensure that when the load applied to the device via the braces is sufficient to initiate slip on the tension diagonal, then the compression diagonal will also slip an equal amount in the opposite direction. Deformation fields of the damper are shown in Fig. 16.

Utilization of this type of geometric deformation in the cross bracing of a building frame displaced laterally has been proposed in a number of different instances as a way to permit substantial controlled energy dissipation (Tyler, 1983). The friction resistance of the device requires a normal force on the sliding interface, and this is achieved through a bolt at the intersection of the diagonal arms. Preliminary tests of a single device in a uniaxial tensioncompression machine were performed to calibrate the device slip load against preload normal force 
(which was quantified in terms of the torque applied to the center bolt). Hence, specified slip loads could be obtained or changed within the model as necessary during testing.

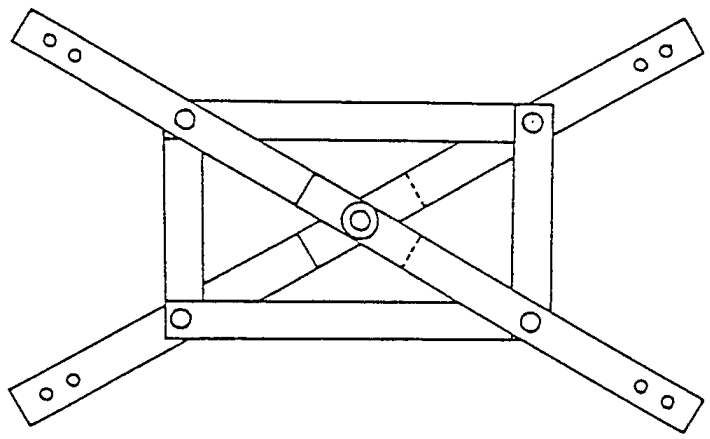

Fig. 15: Pall Friction Device

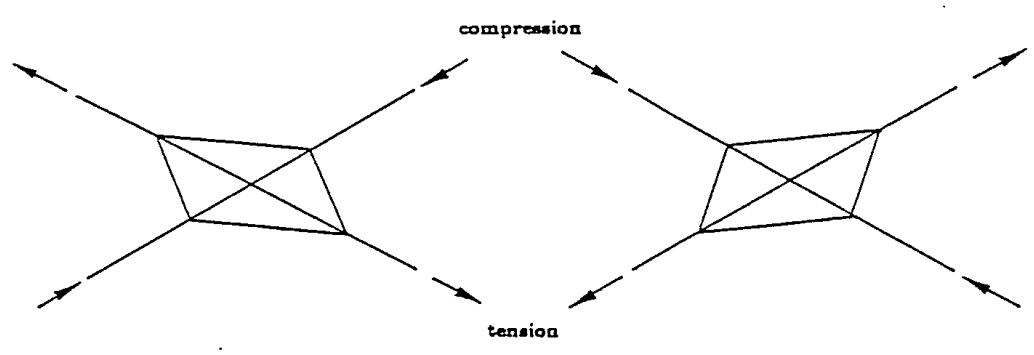

Fig. 16: Deformed Configurations of a Pall Friction Device

Design of the friction dampers for the 9-story model was achieved by meeting several initial criteria (Aiken, 1988) and then determining optimal slip loads through a series of nonlinear timehistory analyses, varying the slip loads and evaluating the response amplitudes. The model with the Pall dampers included is hereafter referred to as the friction-damped braced frame (FDBF).

\section{EARTHQUAKE SIMULATOR TESTS}

With the exception of the Llolleo, Chile, and the La Union, Mexico, motions, the earthquake records used for the FDBF tests were the same as those used in the FD and VD model tests. In a number of cases, however, different input intensities were used for the motions.

\section{Tests and Results}

White-noise and impulse excitations were used to identify the modal frequencies and provide an estimate of the initial structure damping (prior to activation of the friction dampers). The fundamental frequency of the FDBF was identified as $2.23 \mathrm{~Hz}$, and the second mode frequency to be $8.34 \mathrm{~Hz}$. These frequencies were $2.00 \mathrm{~Hz}$ and $6.61 \mathrm{~Hz}$ for the MRF. 
Among the many input motions that were used in the FDBF tests, the most severe was the SCT motion (recorded in Mexico City in the 1985 Michoacan earthquake). This motion has a very narrow-band frequency content, and to obtain a very severe excitation, the signal was arbitrarily time-scaled to shift the narrow spectral peak to the approximate first natural frequency of the FDBF. This resulted in an unusually severe excitation. This technique was used for tests of both the FDBF and the MRF.

Response results for the model subjected to inputs at a range of intensity levels showed the increased energy dissipation, and therefore effectiveness, of the friction devices as the input intensity increases.

A typical hysteresis loop for a bottom floor device during the Miyagi-350 test is shown in Fig. 17. The total force in the device is taken as the sum of the forces in the tension and compression braces, and this is plotted against the slip deformation time history of the device to give the hysteresis loop.

The most significant comparisons of response between the FDBF and the MRF were for the tests using the modified SCT input. For both structural systems, the magnitude of the input was increased until a maximum relative displacement of about 2.8 to 3.0 inches (approx. one percent drift) was obtained at the roof of the model. The maximum peak ground acceleration (PGA) experienced by the FDBF was $0.65 \mathrm{~g}$, and $0.25 \mathrm{~g}$ for the MRF. Fig. 18 shows the profiles of peak floor acceleration and peak story drift (normalized to PGA) for these two input motions. These plots represent response ratios (FDBF/MRF) of 0.50 for acceleration and 0.34 for displacement. Story shear profiles for these two tests are shown in Fig. 19. Approximately 38 percent of the total base shear in the FDBF was carried by controlled nonlinear action in the friction dampers.

\section{SUMMARY}

The seismic performance of a 9-story steel MRF was considerably improved by the inclusion of the friction dampers in its lateral-resisting system. The dissipation characteristics of the friction dampers are reliable, and the devices are not damaged by large loads. The devices become more effective at absorbing energy as the intensity of the input motion increases. Filiatrault, who has also studied the Pall device in shake table experiments, has developed a simplified design procedure for structures containing these devices (1990b).

\section{ADAS ELEMENTS}

Added Damping and Stiffness (ADAS) elements are designed to dissipate energy through the flexural yielding deformation of mild-steel plates. A research program at EERC was undertaken to investigate the behavioral aspects of individual ADAS elements under dynamic loading, and the improvements in response of a three-story ductile steel, moment-resisting frame (MRF) upgraded with ADAS elements and subjected to shake table earthquake ground motions table (Whittaker, 1991). 


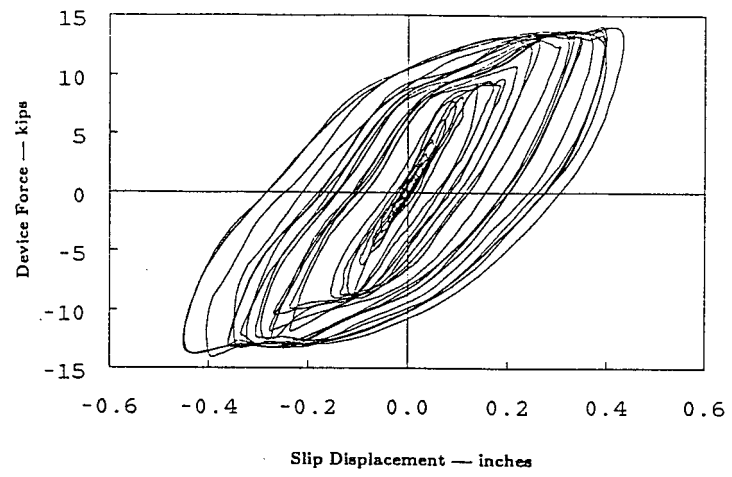

Fig. 17: Level 1 Device Hysteresis, Miyagi - 0.447g Test
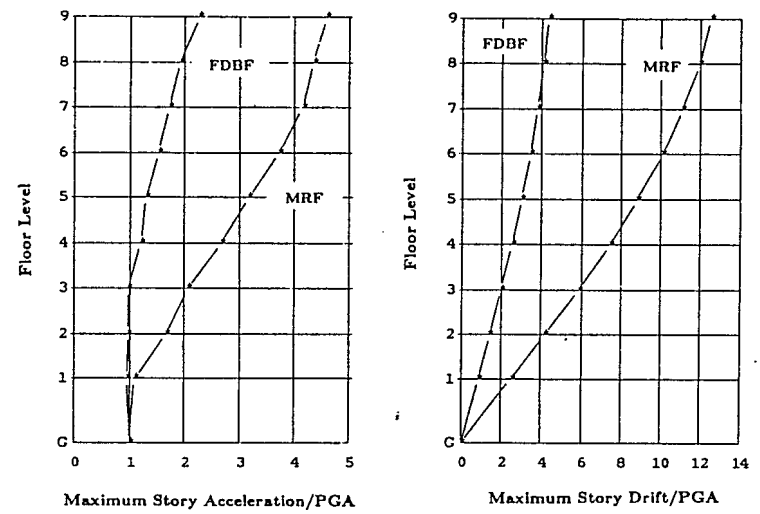

Fig. 18: FDBF and MRF Peak Story Accelerations and Drifts
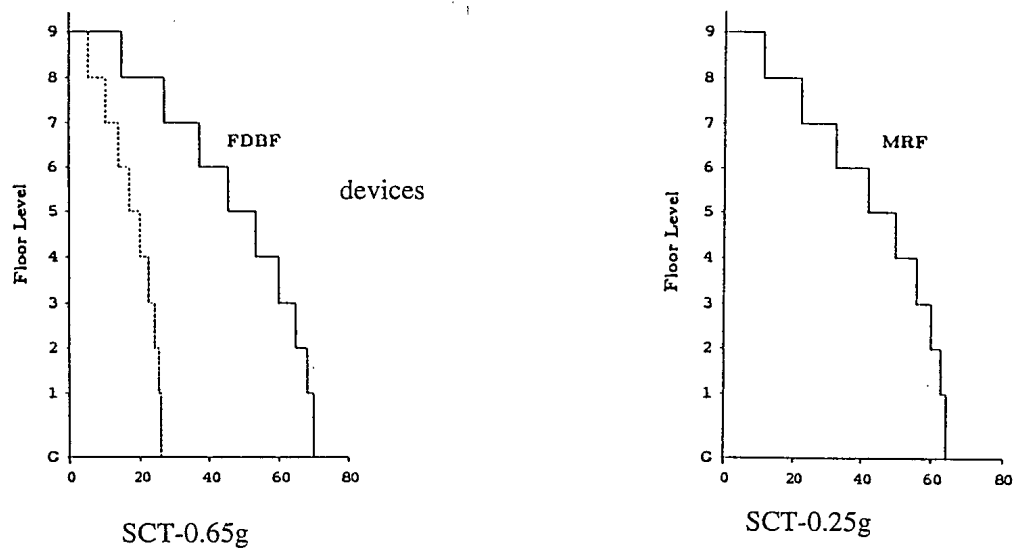

Fig. 19: FDBF and MRF Peak Story Shears 


\section{DESCRIPTION AND TESTING OF ADAS ELEMENTS}

\section{Description}

ADAS elements consist of multiple X-shaped mild steel plates configured in parallel between top and bottom boundary connections (Fig. 20). The ADAS elements used in the test program described here were made from ASTM Grade A-36 steel and consisted of either four, six, or seven plates.

The particular advantage of an X-plate is that, when deformed in double curvature, the plate deformation is uniform over its height, and when deformed into its plastic regime, the yielding will be distributed. A rectangular plate, when deformed plastically in double curvature, will yield only at its ends. This concentration is particularly undesirable both in terms of the amount of energy that can be absorbed by such a deformation pattern and by its inherent lack of stability and repeatability in the plastic range.

The X-plate is a development from triangular plate devices, which were developed in New Zealand (Tyler 1978, Boardman, 1983) and was first developed as a piping support element (Steimer, 1980 and 1981). X-plates have been used as the energy dissipating component of a base isolation system in shake table tests (Steimer, 1984).

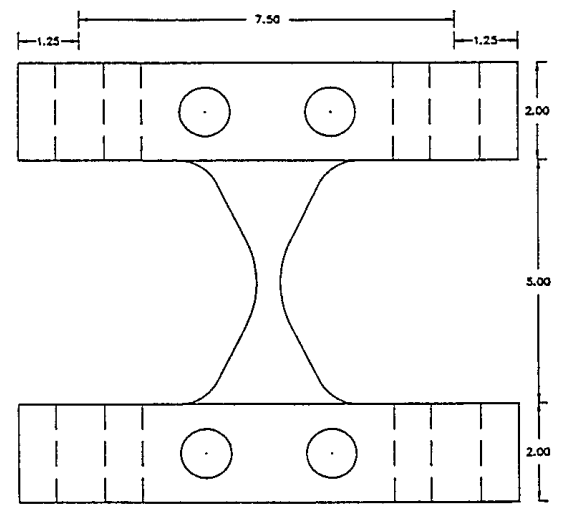

All dimensions in inches

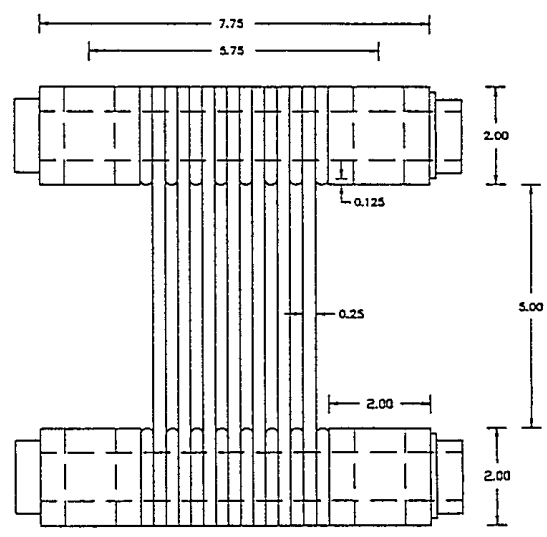

All dimensions in inches

Fig. 20: Added Damping and Stiffness (ADAS) Element

\section{Component Tests}

Dynamic tests of individual ADAS elements were performed. Sinusoidal displacements were imposed on the elements, and the force and deformation responses recorded. A typical hysteresis loop from one of the tests of a 7-plate element is shown in Fig. 21. The primary factors affecting ADAS element behavior are device elastic stiffness $\left(K_{e}\right)$, yield strength $\left(R_{y}\right)$, and yield displacement $\left(\Delta_{y}\right)$. 
The tests showed that: ADAS elements are capable of sustaining more than 100 loading cycles at a deformation amplitude of $3 \Delta_{y}$ with stable response and no signs of degradation; ADAS elements can safely be designed for displacement ranges up to about $10 \Delta_{y}$; and failure of one ADAS element was induced by 15 cycles of loading at an amplitude of $14 \Delta_{y}$. The tests also indicated the importance of rigid boundary connections for successful performance of ADAS elements. Tests performed by Bergman (1987) indicated similar results.

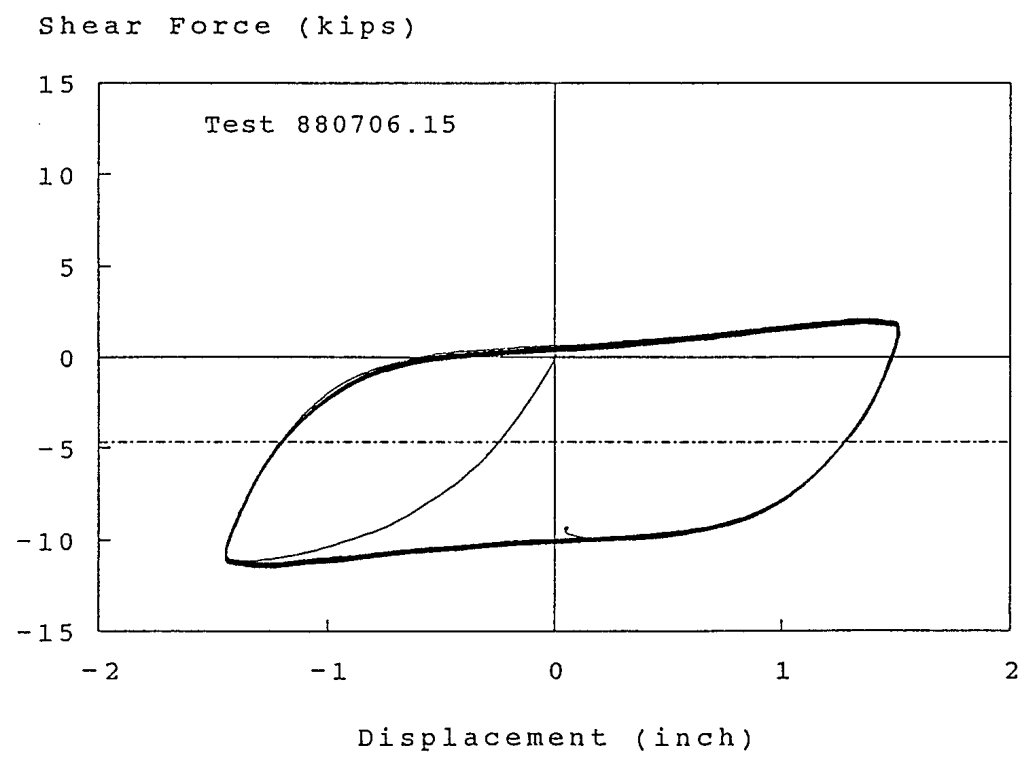

Fig. 21: 7-Plate ADAS Element Hysteretic Behavior

\section{EARTHQUAKE SIMULATOR TESTS \& RESULTS}

\section{Test Model}

A 3-story, steel MRF was used for the earthquake simulator tests of an ADAS-upgraded structure (Fig. 22). The model had a first-story height of $6 \mathrm{ft} .8$ in., and the upper two stories were $5 \mathrm{ft} .4 \mathrm{in}$. high. The model was assumed to have a scale factor of one, i.e., it was considered as fullscale for the experiments, which meant that there was no time-scaling of the input motions. It satisfied the $1988 \mathrm{UBC}$ strength and stiffness requirements for a ductile, moment-resisting space frame on a rock site. The total test weight was 90 kips (30 kips per floor). The ADAS elements were installed at the top of chevron brace sub-assemblages that were added to the MRF. The sizes of the ADAS elements were varied up the structure, with 7-plate devices at the bottom floor, 6plate devices at the second floor, and 4-plate devices at the top floor.

$\underline{\text { Results }}$

Earthquake tests were conducted of the MRF both with the ADAS element upgrade (referred to as ADAS-frame) and then again in its bare configuration (no any ADAS elements). This provided experimental data for direct comparisons of the MRF and the ADAS-frame. 


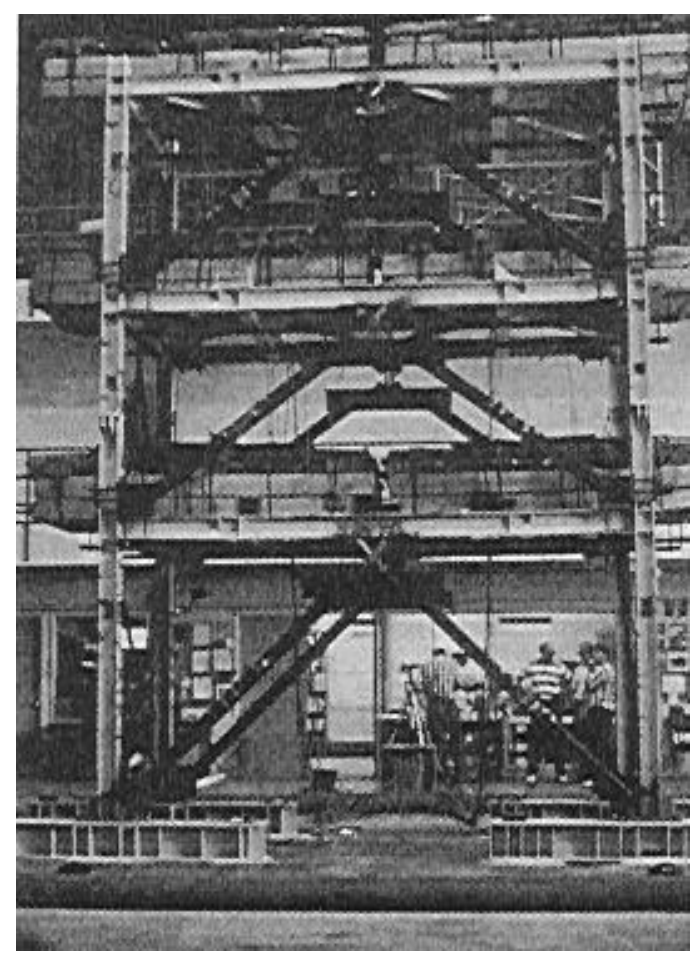

Fig. 22: MRF Retrofitted With ADAS Elements

The first phase of the shake table study involved free-vibration and white-noise excitation system identification tests of both structures. The addition of the chevron bracing and the ADAS elements increased the MRF first-mode frequency from $1.35 \mathrm{~Hz}$ to $2.12 \mathrm{~Hz}$.

Although numerous earthquake tests of both structures were performed, only one test of each structure will be discussed in detail here. The ground motion used was the Llolleo N10E record from the 1985 Chile earthquake, which was input to the MRF with a PGA of $0.13 \mathrm{~g}$ and input to the ADAS-frame with PGAs of $0.13 \mathrm{~g}$ and $0.56 \mathrm{~g}$. These tests are referred to as Chile-13 and Chile-56, with effective peak accelerations (EPAs) of $0.10 \mathrm{~g}$ and $0.46 \mathrm{~g}$, respectively. The response envelopes for the structures subjected to these inputs are presented in Tables 1,2, and 3. The peak interstory drift index (ISI) for the MRF was 1.3 percent in the Chile-13 test; for the ADAS-frame it was 0.46 percent in the Chile-13 test and 2.0 percent in the Chile-56 test. Responses to the Chile-13 test are compared in Fig. 23. The response of the MRF to a ground motion with an EPA of only $0.10 \mathrm{~g}$ was clearly inadequate. The addition of the ADAS-bracing assemblage significantly improved the overall performance of the structure and enabled it to withstand a much bigger EPA $(0.46 \mathrm{~g})$ with acceptable drift responses.

\section{SUMMARY}

The research program demonstrated that ADAS elements possess characteristics that make them suitable for use as energy dissipation devices in new and existing buildings. One practical configuration for installing ADAS devices in a building is in conjunction with a chevron brace assemblage as was used in the test structure studied. The chevron assemblage must be designed 
using capacity principles, based on an ADAS element strength of at least two times the device yield strength. The performance of an ADAS element is influenced by the degree of restraint at its head and base, and the design of these connection details must take this factor into consideration. Results of tests of a structure that, while compliant with the requirements of the $1988 \mathrm{UBC}$, nonetheless underwent excessive drifts under even moderate excitations, clearly indicate the benefit of the addition of ADAS elements and bracing to the lateral system in improving its seismic resistance.
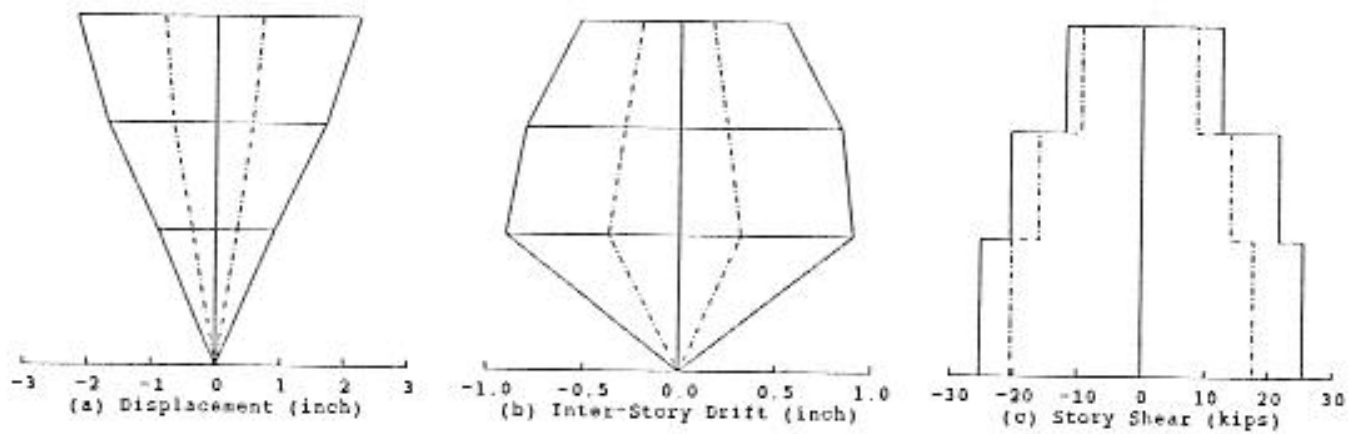

(solid $=\mathrm{MRF} ;$ dash-dot $=\Lambda \mathrm{DAS}$ Frame)

Fig. 23: MRF and ADAS Frame Response Comparisons, Chile-13 Input

\begin{tabular}{|c|c|c|c|c|c|c|}
\hline \multirow{2}{*}{ Floor/Story } & \multicolumn{2}{|c|}{ Roof/3 } & \multicolumn{2}{c|}{$3 / 2$} & \multicolumn{2}{c|}{$2 / 1$} \\
\cline { 2 - 7 } & Max. & Min. & Max. & Min. & Max. & Min. \\
\hline \hline Lateral Displ. (in.) & 2.21 & -2.17 & 1.69 & -1.68 & 0.89 & -0.90 \\
Time (sec.) & 8.38 & 6.44 & 8.38 & 6.45 & 6.83 & 6.46 \\
\hline Interstory Drift (in.) & 0.54 & -0.52 & 0.83 & -0.80 & 0.89 & -0.90 \\
Interstory Drift Index (\%) & 0.84 & 0.81 & 1.30 & 1.25 & 1.11 & 1.13 \\
Time (sec.) & 8.38 & 6.42 & 8.38 & 6.43 & 6.83 & 6.46 \\
\hline Story Shear (k) & 12.4 & -12.0 & 21.3 & -20.6 & 25.0 & -25.3 \\
Story Shear/Total Wt. (\%) & 13.5 & 13.0 & 23.1 & 22.4 & 27.2 & 27.4 \\
Time (sec.) & 8.38 & 6.42 & 8.38 & 6.43 & 6.84 & 6.43 \\
\hline Inertia Force (k) & 12.0 & -12.4 & 9.3 & -9.2 & 8.0 & -7.3 \\
Time (sec.) & 6.42 & 8.38 & 6.46 & 5.27 & 18.13 & 5.26 \\
\hline Overturn. Moment (k-in.) & 795 & -769 & 2159 & -2085 & 4145 & -4104 \\
Time (sec.) & 8.38 & 6.42 & 8.37 & 6.42 & 8.37 & 6.42 \\
\hline
\end{tabular}

Table 1: MRF Response Envelopes, Chile-13 Input 


\begin{tabular}{|c|c|c|c|c|c|c|}
\hline \multirow{2}{*}{ Floor/Story } & \multicolumn{2}{|c|}{ Roof/3 } & \multicolumn{2}{c|}{$3 / 2$} & \multicolumn{2}{c|}{$2 / 1$} \\
\cline { 2 - 7 } & Max. & Min. & Max. & Min. & Max. & Min. \\
\hline \hline Lateral Displ. (in.) & 0.71 & -0.81 & 0.56 & -0.67 & 0.32 & -0.37 \\
Time (sec.) & 12.43 & 14.92 & 12.44 & 14.92 & 12.45 & 14.92 \\
\hline Interstory Drift (in.) & 0.17 & -0.20 & 0.25 & -0.29 & 0.32 & -0.37 \\
Interstory Drift Index (\%) & 0.27 & 0.31 & 0.39 & 0.45 & 0.40 & 0.46 \\
Time (sec.) & 13.01 & 12.73 & 13.00 & 14.92 & 12.45 & 14.92 \\
\hline Story Shear (k) & 8.7 & -9.5 & 14.0 & -16.2 & 17.6 & -20.5 \\
Story Shear/Total Wt. (\%) & 9.2 & 10.0 & 14.7 & 17.0 & 18.5 & 21.5 \\
Time (sec.) & 13.00 & 12.72 & 12.43 & 14.92 & 12.44 & 14.92 \\
\hline Inertia Force (k) & 9.5 & -8.7 & 7.9 & -6.3 & 5.1 & -4.7 \\
Time (sec.) & 12.72 & 13.00 & 14.92 & 12.44 & 12.78 & 14.65 \\
\hline Overturn. Moment (k-in.) & 555 & -606 & 1446 & -1570 & 2798 & -3211 \\
Time (sec.) & 13.00 & 12.72 & 13.00 & 14.92 & 12.43 & 14.92 \\
\hline
\end{tabular}

Table 2: ADAS-Frame Response Envelopes, Chile-13 Input

\begin{tabular}{|c|c|c|c|c|c|c|}
\hline \multirow{2}{*}{ Floor/Story } & \multicolumn{2}{|c|}{ Roof/3 } & \multicolumn{2}{c|}{$3 / 2$} & \multicolumn{2}{c|}{$2 / 1$} \\
\cline { 2 - 7 } & Max. & Min. & Max. & Min. & Max. & Min. \\
\hline \hline Lateral Displ. (in.) & 2.63 & -3.17 & 2.16 & -2.65 & 1.30 & -1.60 \\
Time (sec.) & 12.54 & 5.52 & 12.54 & 12.86 & 12.54 & 12.86 \\
\hline Interstory Drift (in.) & 0.58 & -0.66 & 0.90 & -1.08 & 1.30 & -1.60 \\
Interstory Drift Index (\%) & 0.90 & 1.03 & 1.40 & 1.69 & 1.62 & 2.00 \\
Time (sec.) & 5.18 & 5.50 & 5.17 & 5.52 & 12.54 & 12.86 \\
\hline Story Shear (k) & 21.6 & -24.1 & 34.7 & -41.2 & 46.8 & -54.4 \\
Story Shear/Total Wt. (\%) & 22.7 & 25.3 & 36.5 & 43.4 & 49.3 & 57.3 \\
Time (sec.) & 5.17 & 5.49 & 5.17 & 5.51 & 12.53 & 12.85 \\
\hline Inertia Force (k) & 24.1 & -21.6 & 21.5 & -17.0 & 15.4 & -14.5 \\
Time (sec.) & 5.49 & 5.17 & 12.86 & 12.54 & 12.84 & 14.66 \\
\hline Overturn. Moment (k-in.) & 1383 & -1541 & 3596 & -4140 & 7020 & -8106 \\
Time (sec.) & 5.16 & 5.49 & 5.16 & 5.50 & 12.53 & 5.50 \\
\hline
\end{tabular}

Table 3: ADAS-Frame Response Envelopes, Chile-56 Input 


\section{STEEL MRF RETROFIT WITH FRICTION-SLIP DEVICES}

Subsequent to shake table tests of the 9-story steel model with Pall friction dampers (Section 2.), another type of friction device was developed for use in structures as part of a chevron bracing system (Giacchetti, 1989). This section describes the development and testing of this device, its inclusion in a steel MRF, and shake table tests of the retrofitted structure.

\section{DESCRIPTION AND TESTING OF DEVICES}

\section{Description}

The friction-slip device (FSD) consists of two U-shaped steel casings and a sliding piece located between the casings (Fig. 24). The interface between the inner and outer pieces is faced with a high-performance brake-pad material, and the normal force to the friction surface is developed by prestressed bolts..

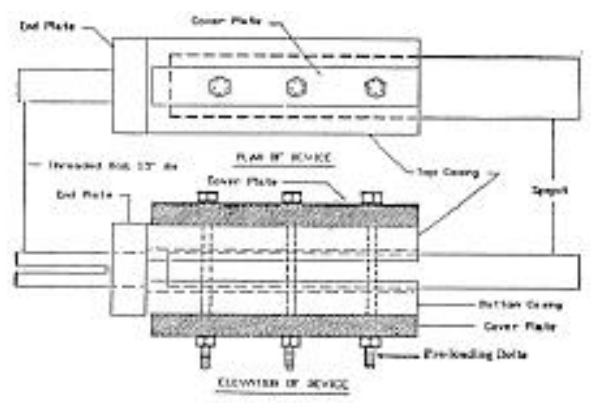

Fig. 24: Friction-Slip Device

\section{Component Tests}

A single FSD was subjected to extensive dynamic tests in a uniaxial tension-compression machine to investigate its behavior characteristics. Possible factors affecting performance, such as variation in bolt preload, temperature, rate of sliding, and misalignment were all quantified. For the initial FSD design, misalignment of the inner and outer pieces was found to be a potential problem, so the design was modified. The design was improved to include oil-impregnated bearings acting as guide-plates between the inner and outer units. This refined design was subjected to dynamic tests in a one-story, one-bay, chevron-braced subassemblage. These tests verified the refined design, and then the FSDs were installed in the test structure.

\section{EARTHQUAKE SIMULATOR TESTS \& RESULTS}

\section{Test Model}

The test structure was originally designed in accordance with the 1979 UBC and the 1981 Japanese Aseismic Code. The approximately 1/3-scale ductile steel MRF was two bays in plan, 6 stories high, with a lightweight composite floor system (Fig. 25). Tests of the structure in momentresisting, concentrically-braced, and eccentrically-braced configurations showed that the MRF suffered excessive drifts under moderate and severe ground motions (Whittaker, 1990). 
The FSDs were included in the model as part of a chevron bracing system. They were located at the bottom end of each brace, adjacent to the beam-column-brace connection (Fig. 26). By placing the devices in this location, any deformations of the FSDs out-of-plane with the longitudinal axis of the bracing would be negligible and not detrimental to their sliding behavior.
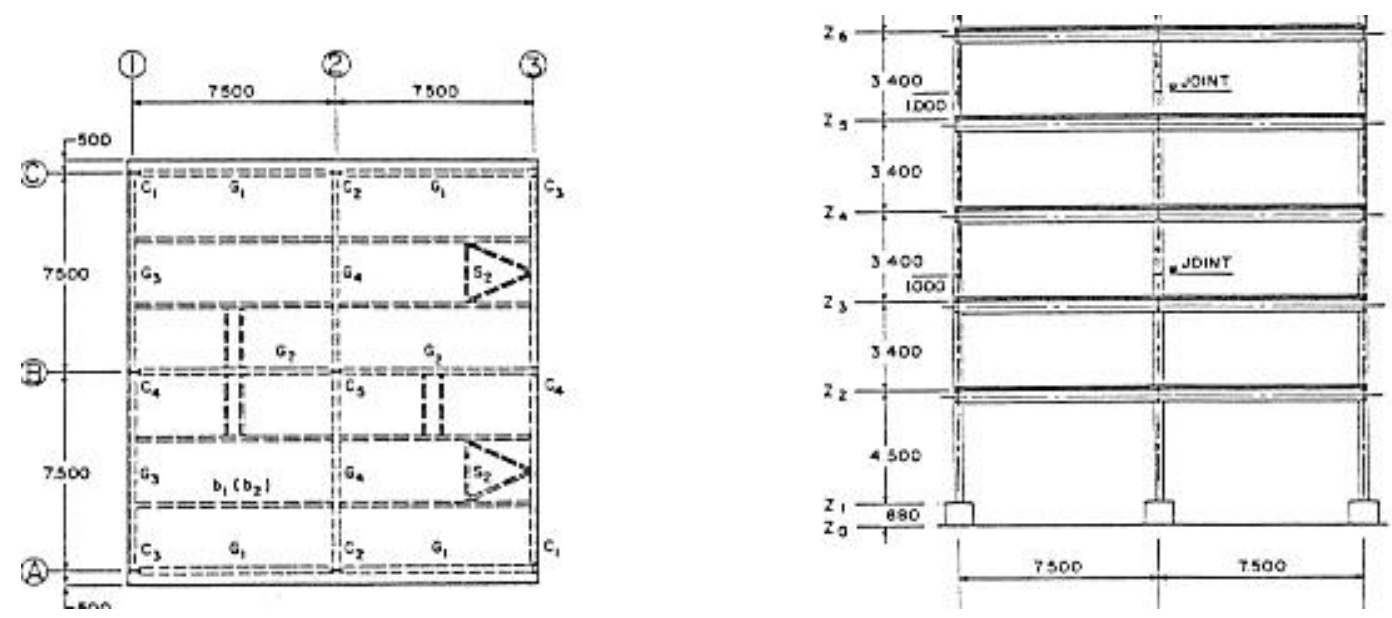

Fig. 25: Plan and Elevation of 6-Story Ductile MRF
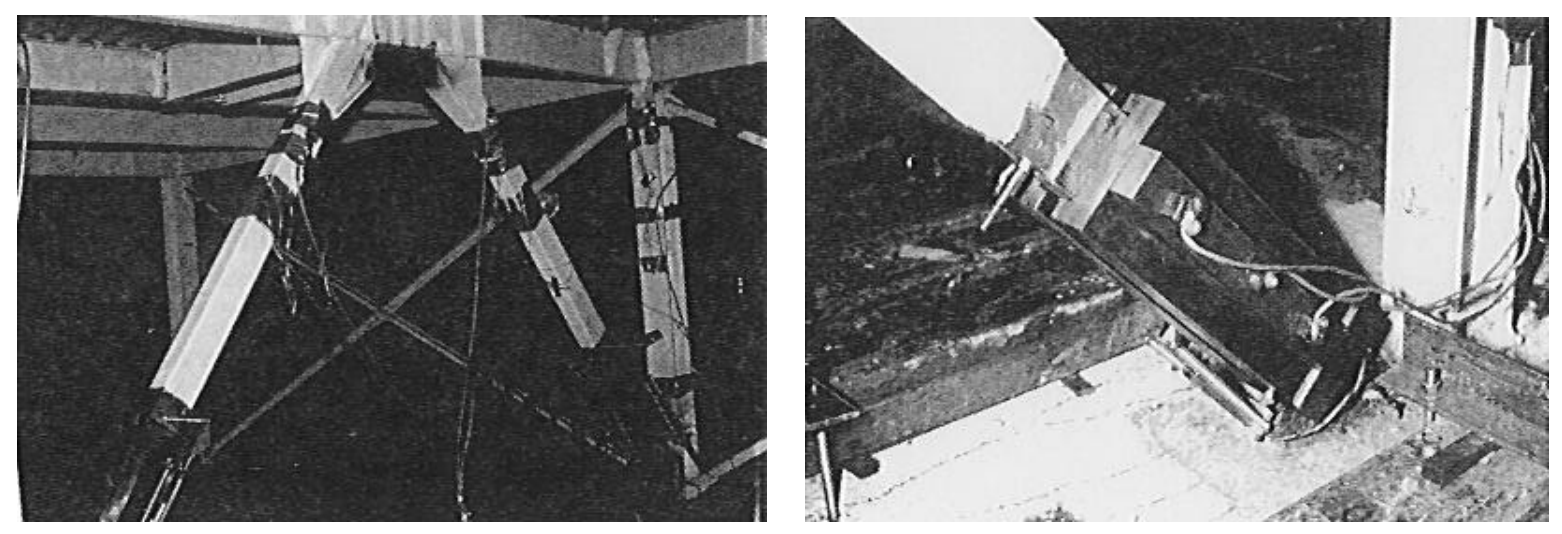

Free vibrations of the MRF and FSD-frame induced by pulse excitations were analyzed to determine the dynamic characteristics of the structural systems. Natural frequencies were found to be $1.45 \mathrm{~Hz}$ for the MRF, and $2.87 \mathrm{~Hz}$ for the FSD-frame. The addition of the chevron bracing and the FSDs significantly stiffened the test structure.

\section{$\underline{\text { Results }}$}

The MRF and FSD-frame were both subjected to the same set of earthquake inputs, and the FSD-frame was also subjected to more than 35 severe and very severe input motions. Only a few tests of each structure are discussed here. Peak response quantities of the MRF subjected to four different inputs are listed in Table 4, and of the FSD-frame subjected to two different inputs in Table 5. Inelastic behavior of the MRF commenced for motions of about EPA $=0.20 \mathrm{~g}$, but excessive interstory drifts (ISDs) occurred even for motions with EPAs less than 0.10g. An 
example of MRF inelastic behavior is the third-floor story shear-ISD relationship shown in Fig. 27 for the Taft-34 (EPA $=0.27 \mathrm{~g}$ ) input. The maximum ISI for this test was 2.5 percent, which occurred at the third floor. For the SCT-43 test $(\mathrm{EPA}=0.21 \mathrm{~g})$, the peak ISI was 4.5 percent.

\begin{tabular}{|c|c|c|c|c|c|c|}
\hline \multirow{2}{*}{ SIGNAL } & \multirow{2}{*}{$\begin{array}{c}\text { Max. } \\
\text { Interstory } \\
\text { Drift } \\
\text { (inches) }\end{array}$} & \multicolumn{2}{|c|}{$\begin{array}{l}\text { Max. Interstory } \\
\text { Drift Index }\end{array}$} & \multirow{2}{*}{$\frac{\text { MaxBaseShear }}{W}$} & \multirow{2}{*}{$\begin{array}{l}\text { PGA } \\
(\mathrm{g})\end{array}$} & \multirow{2}{*}{$\begin{array}{c}\text { EPA } \\
(\mathrm{g})\end{array}$} \\
\hline & & $(\%)$ & story & & & \\
\hline Taft-09 & 0.18 & 0.41 & 4 & 0.11 & 0.09 & 0.07 \\
\hline Taft-10 & 0.48 & 1.14 & 4 & 0.30 & 0.10 & 0.09 \\
\hline Taft-34 & 1.00 & 2.45 & 3 & 0.41 & 0.34 & 0.27 \\
\hline SCT-43 & 1.85 & 4.53 & 3 & 0.47 & 0.43 & 0.21 \\
\hline
\end{tabular}

Table 4: MRF Interstory Drift and Shear Maxima

\begin{tabular}{|c|c|c|c|c|c|c|}
\hline \multirow{2}{*}{ SIGNAL } & \multirow{2}{*}{$\begin{array}{l}\text { Max. } \\
\text { Interstory } \\
\text { Drift } \\
\text { (inches) }\end{array}$} & \multicolumn{2}{|c|}{$\begin{array}{l}\text { Max. Interstory } \\
\text { Drift Index }\end{array}$} & \multirow{2}{*}{$\frac{\text { MaxBaseShear }}{W}$} & \multirow{2}{*}{$\begin{array}{l}\text { PGA } \\
(\mathrm{g})\end{array}$} & \multirow{2}{*}{$\begin{array}{c}\text { EPA } \\
(\mathrm{g})\end{array}$} \\
\hline & & $(\%)$ & story & & & \\
\hline Taft-86 & 0.72 & 1.74 & 4 & 0.44 & 0.86 & 0.72 \\
\hline Chile-100 & 0.61 & 1.51 & 5 & 0.48 & 1.00 & 0.65 \\
\hline
\end{tabular}

Table 5: FSD-Frame Interstory Drift and Shear Maxima

After the inclusion of the FSD-chevron brace system, the poor performance of the MRF was considerably improved. The Taft-86 (EPA $=0.72 \mathrm{~g})$ input caused a peak ISD of only 1.74 percent, while the Chile-100 (EPA $=0.65 \mathrm{~g})$ induced a maximum ISD of 1.51 percent. Third-floor story shear vs. ISD, shear in the ductile MRF vs. ISD, and chevron brace shear (resolved FSD slip force) vs. ISD relationships for the Taft-86 input are all shown in Fig. 28. It is clear that there is no inelastic action in the primary MRF, and that the energy dissipation represented in the story shearISD plot is due to the FSDs alone.

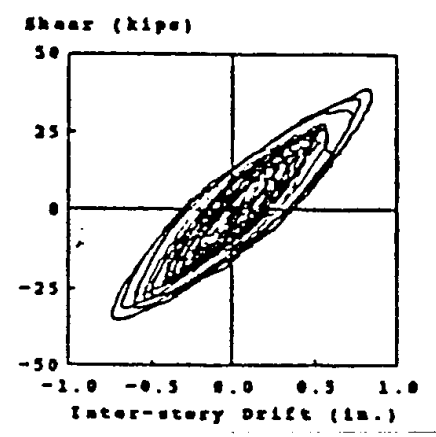

Fig. 26: MRF 3rd Floor Story Shear vs. ISD, Taft-34 Input 

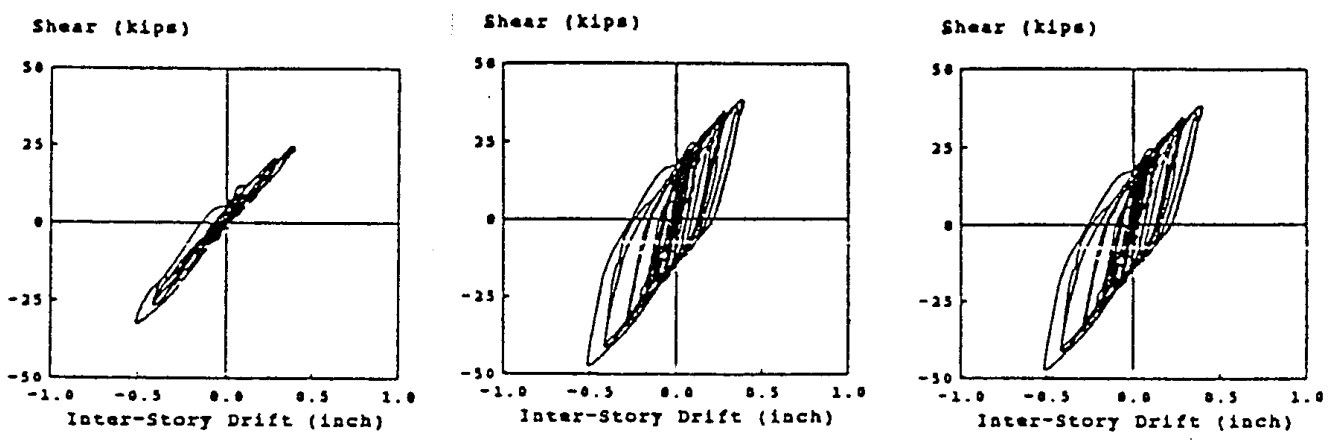

Fig. 27: FSD-Frame 3rd Floor Story Shear vs. ISD Relationships, Taft-86 Input

\section{SUMMARY}

A friction energy dissipator was developed and used to successfully retrofit a ductile steel MRF, providing the structure with a substantially greater energy dissipation capability and greater stiffness to control drifts during severe loadings. Inelastic action in primary structural members of the MRF was avoided and energy dissipated instead in the friction devices within a chevron bracing system. The inherent lack of ductility in a chevron system is overcome by including FSDs in the bracing and using capacity design methods. The FSD-chevron system represents a significant improvement over conventional concentrically-braced, or even eccentrically-braced structural systems by concentrating energy dissipation in elements best suited to this task and not by demanding inelastic action in primary gravity load-resisting structural members.

\section{SMALL-SCALE EARTHQUAKE SIMULATOR STUDIES}

\section{FLUOR-DANIEL ENERGY-DISSIPATING RESTRAINT}

This section presents a summary of the test results of the Fluor Daniel, Inc. Energy Dissipating Restraint (EDR) and tests studying the use of Nickel Titanium shape memory alloy (NiTi or Nitinol) as an energy dissipating element. Both series of tests were performed on the same small-scale 3-story steel frame. More details of the results of these tests are provided by Richter (1990) and Aiken (1992).

\section{DESCRIPTION OF TEST FACILITY AND MODEL STRUCTURE}

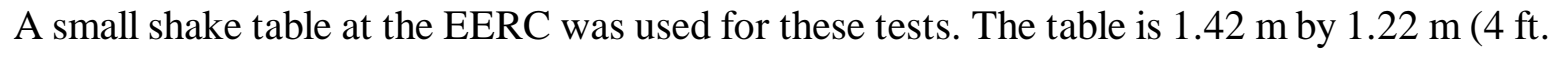
8 in $\mathrm{x} 4 \mathrm{ft}$.) in plan, with one horizontal degree of freedom and a payload capacity of $45 \mathrm{kN}$ (10 kips). The model was a three-story steel moment-resisting frame of all-welded construction. The model was $0.91 \mathrm{~m} \times 1.22 \mathrm{~m}$ (3 ft x $4 \mathrm{ft}$.) in plan and the total weight was $18.9 \mathrm{kN}$ (4.02 kips) equally distributed between the floors. The damping of the bare model was 0.5 percent, and the three translational frequencies in the direction of testing were $2.6 \mathrm{~Hz}, 10.9 \mathrm{~Hz}$, and $24.5 \mathrm{~Hz}$. 


\section{ENERGY DISSIPATING RESTRAINT}

The Energy Dissipating Restraint (EDR) was originally developed as a seismic restraint device for the support of piping systems in nuclear power plants. The mechanism of the EDR is sliding friction through a range of motion with a stop at the end of that range of motion. A full description of the EDR mechanical behavior and detailed diagrams of the device are given by Nims (1993) elsewhere in this issue. The features of the device are its self-centering capability and that the frictional force is proportional to the displacement. Depending on the spring constant of the core, the initial slip load, the configuration of the core, and the gap size, several different types of hysteretic behavior are possible. Two typical test hysteresis loops for different adjustments of the device are shown in Fig. 29.

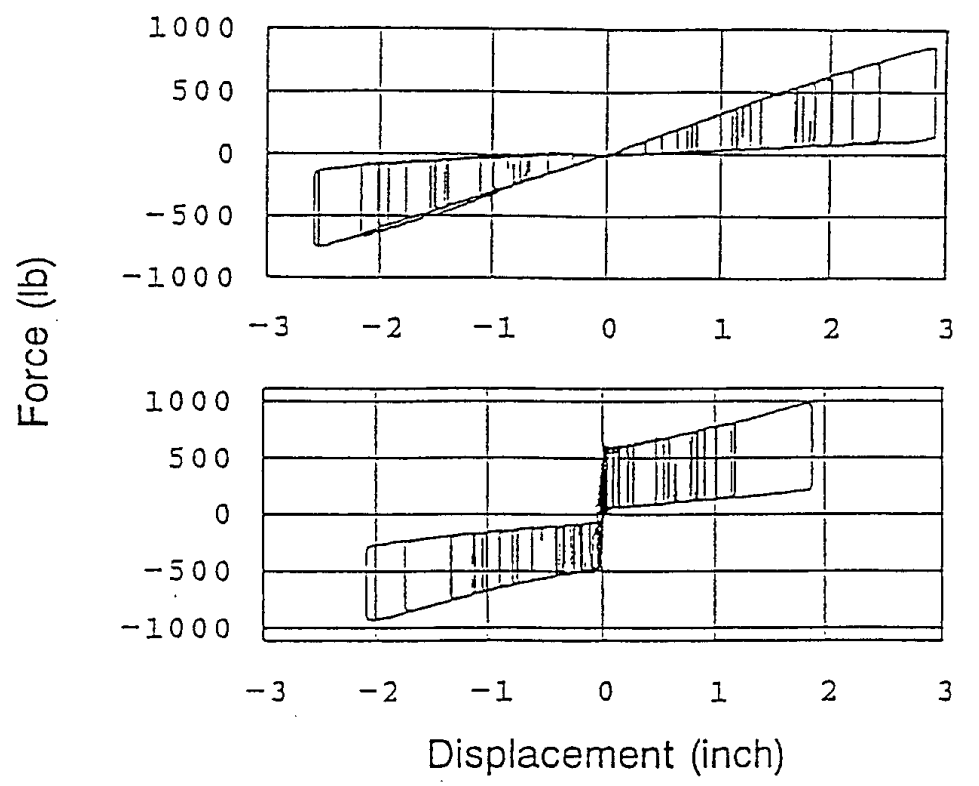

Fig. 28: Hysteresis Loop Shapes for Different EDS Adjustments

\section{$\underline{\text { EDR Test Program }}$}

The EDR frame tests used two earthquake ground motions: El Centro (1940, S00W component, 1/2-time scale) and Zacatula (1985 Michoacan). The El Centro signal has a strong initial pulse while the Zacatula signal is more regular.

Two EDRs were mounted in each of the three stories of the model. Sketches of the model without and with the EDRs installed are shown in Figs. 30 and 31. A view of the EDRs installed in the second level of the model is shown in Fig. 32.

The principal variable changed during the testing was the initial slip load, and, for the majority of the tests performed, the slip load distribution was uniform throughout the model. In addition to the tests with the device in the self-centering configuration, a series of tests with the EDR configured to act as a simple Coulomb device were also performed. 


\section{$\underline{\text { Summary of Test Results }}$}

Figs. 33a and $\mathrm{b}$ show profiles of the peak accelerations, interstory drifts and displacements relative to the ground for the El Centro $(\mathrm{PGA}=0.33 \mathrm{~g})$ and the Zacatula $(\mathrm{PGA}=0.36 \mathrm{~g})$ inputs. On each figure, the response of the bare frame and the EDR with slip loads of 335, 555, 890, and 1335 $\mathrm{N}(75,125,200$, and $300 \mathrm{lbs})$ are compared.

The overall effect of the EDR was to substantially reduce the model deformations and interstory drifts. Interstory drifts and displacements consistently decreased with increasing slip load. Acceleration trends were not as well defined.

Part of the change in structural response was due to the change in the stiffness of the structure with the EDRs in place and part was due to the additional damping the EDRs added to the structure. The change in stiffness was substantial, with the fundamental frequency being $3.9 \mathrm{~Hz}$ for the EDR frame $(2.6 \mathrm{~Hz}$ for the bare frame). The shift in frequency depended on the slip load, the slip load configuration, and the frequency content of the input.

A series of linear-elastic response spectrum analyses were used to approximately segregate the effects of damping and stiffness. The response spectrum analysis was performed using the measured predominant frequency and mode shape for the EDR frame, but the damping was taken as that of the bare frame. The response spectrum results show the relative displacement of the frame with the shifted frequency and changed mode shape, but with the 0.5 percent damping of the bare frame. This approach identifies the relative effects of added damping and added stiffness to the response of the model. Because the mode shape does not change a great deal as the slip load varies, all the results can be normalized to one spectrum analysis curve. The reduction in response below this level is due to the added hysteretic damping of the EDRs. Fig. 34 shows the results of a series of response spectrum analyses for the Zacatula signal. These figures indicate the seminal result of the EDR testing: the additional damping provided by the EDR significantly reduces the structural response. It can be seen from these figures that the damping contributes substantially to the reduction in relative displacement and that the higher the slip load the greater the displacement response reduction. 

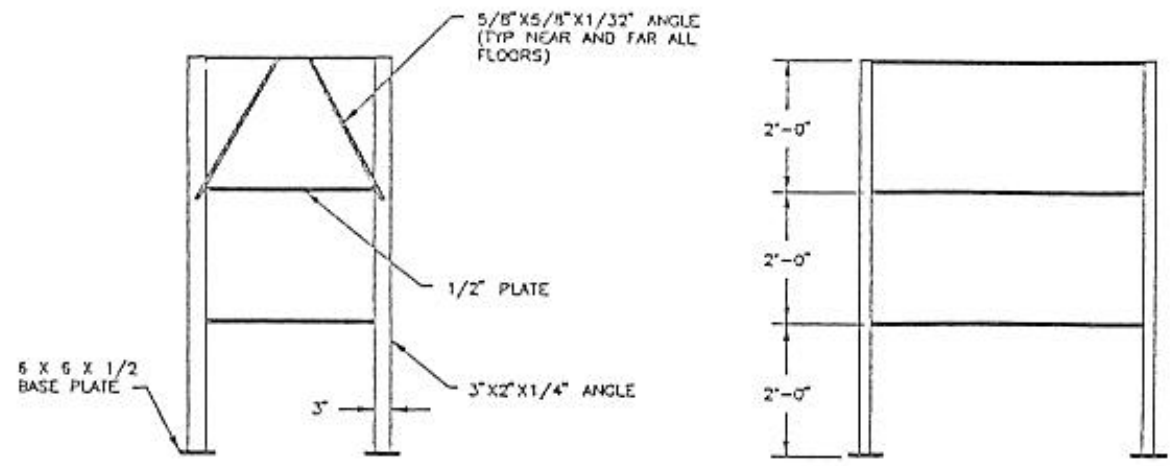

Section

Shaking Elevation

Fig. 29: Bare Frame

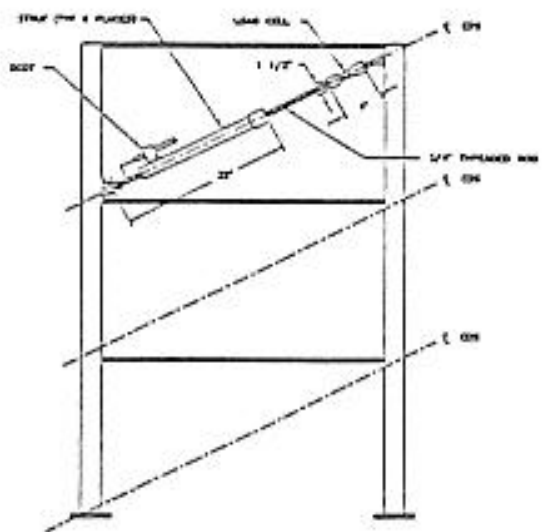

Fig. 30: Frame with Energy Dissipating Restraints

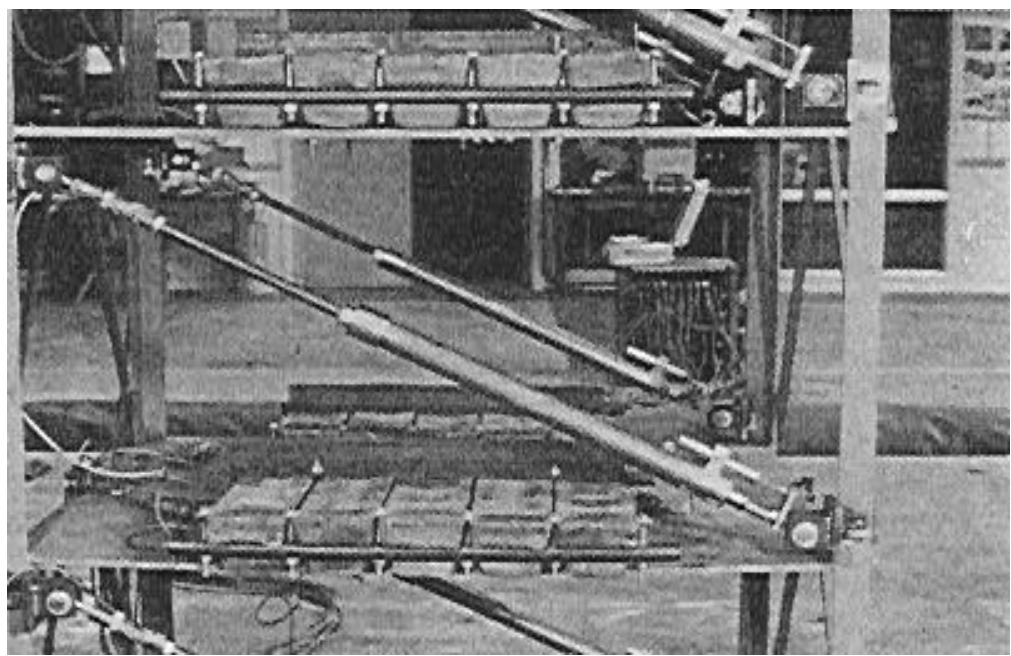

Fig. 31: View of EDRs Installed at Second Level of Frame 
(a) El Centro
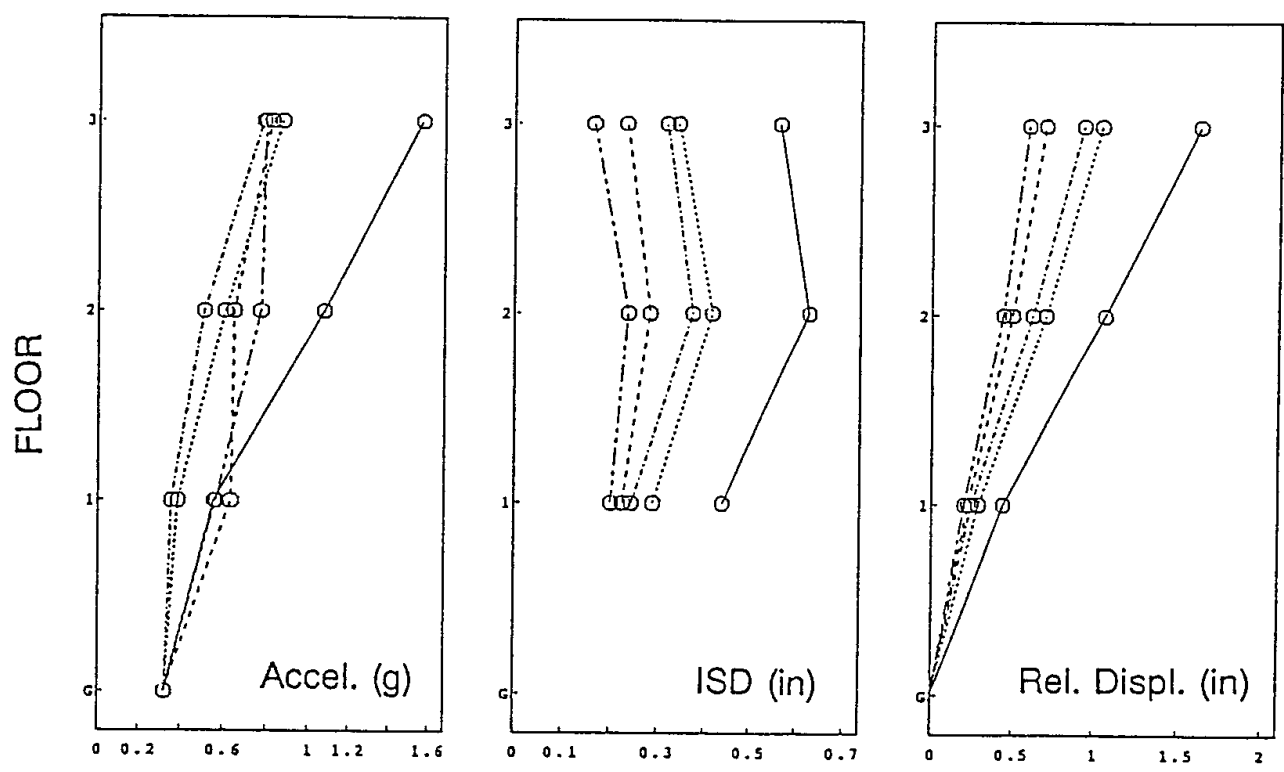

Solid: Bare Frame Dotted: EDS.75 Dot-Dash: EDS.125 Dashed: EDS.200 Dot-Dot-Dash: EDS.300

(b) Zacatula
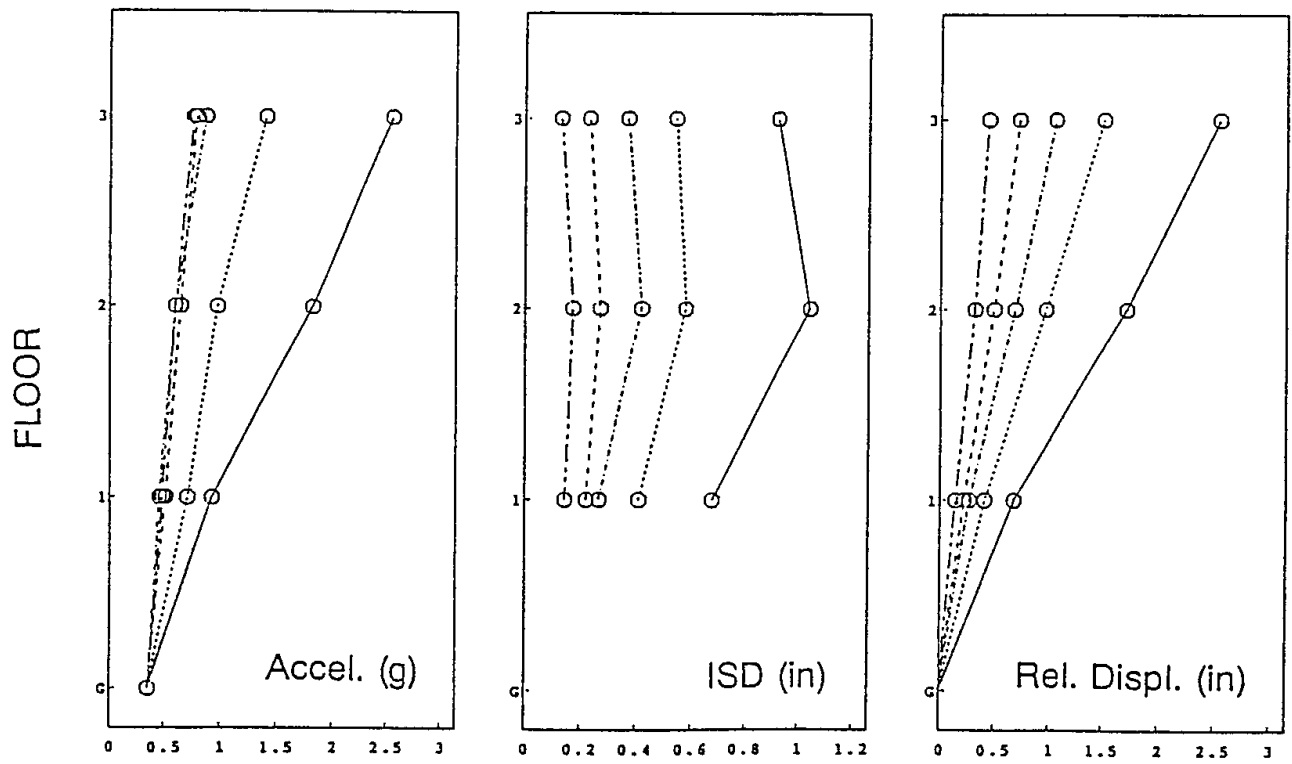

Solid: Bare Frame Dotted: EDS.75 Dot-Dash: EDS.125 Dashed: EDS.200 Dot-Dot-Dash: EDS.300

Fig. 32: EDR Frame Response Profiles 


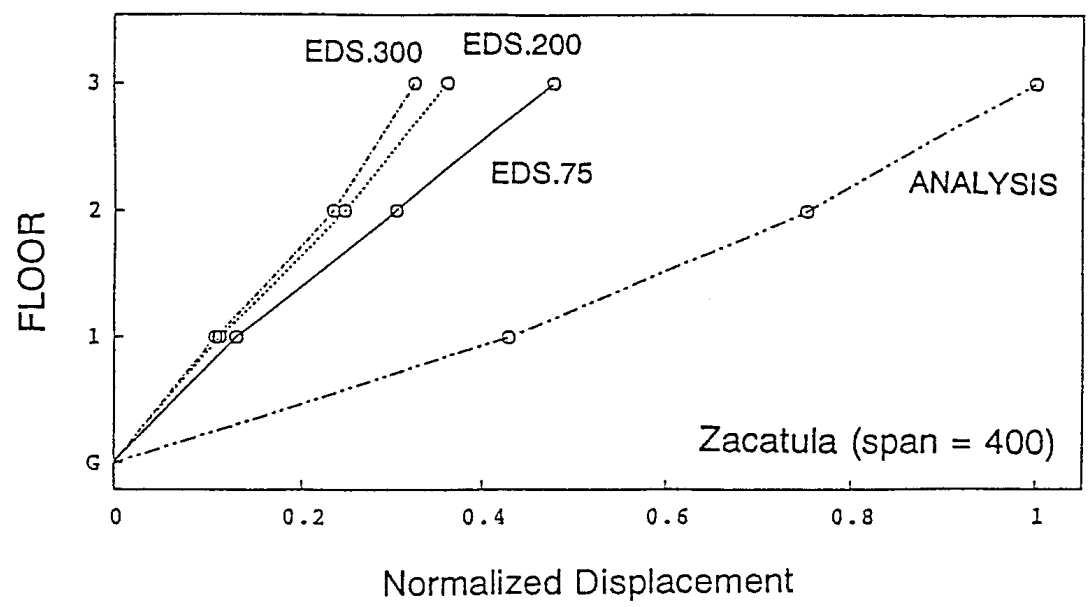

Fig. 33: Effect of Damping on Response - Experimental and Analytical Response Profiles

One advantage of the EDR is that it can be effective at low levels of seismic input or for wind loading, while also being effective at high seismic inputs. This is because the slip force and thus the energy dissipated is proportional to the displacement of the EDR. Another advantage is that the self-centering behavior would tend to reduce permanent offsets if the structure were deformed inelastically.

\section{NiTi SHAPE-MEMORY ALLOY DAMPERS}

The shape memory effect in metals was first observed in the 1930s. In 1962, researchers at the Naval Ordinance Laboratory observed the phenomenon in Nickel-Titanium (NiTi, or Nitinol). Shape-memory alloys (SMAs) have the capacity to undergo large strains and subsequently recover their initial configurations. The basis for this behavior is that, rather than deforming in the usual manner of metals, shape-memory alloys undergo transformations from the austenitic to the martensitic crystal phase (Hodgson, 1988).

Among the growing number of applications of SMAs, the largest single use to date has been in hydraulic pipe couplings. The coupling is cooled to expand its diameter and assembled. Then as it warms to room temperature it recovers its smaller diameter and locks. Other SMA applications are circuit-board connectors, eyeglass frames (with shape memory or superelastic properties), blood clot filters that are inserted into veins and expand due to body temperature, and a number of other medical and dental applications. Sasaki (1989) studied the suitability of Nitinol for energy dissipation under seismic-type loading, and investigated flexural, torsional, shear, and axial modes of deformation. Graesser (1991) and Witting (1992) have continued the studies of shape memory alloys for energy dissipation applications in structures.

In most current commercial applications, the phase change is temperature induced, however, it can be stress induced at room temperature if the Nitinol has the appropriate formulation and treatment. This stress-induced phase change phenomenon is referred to as superelasticity. Fig. 35 illustrates the theoretical behavior of Nitinol as it is loaded in tension. 


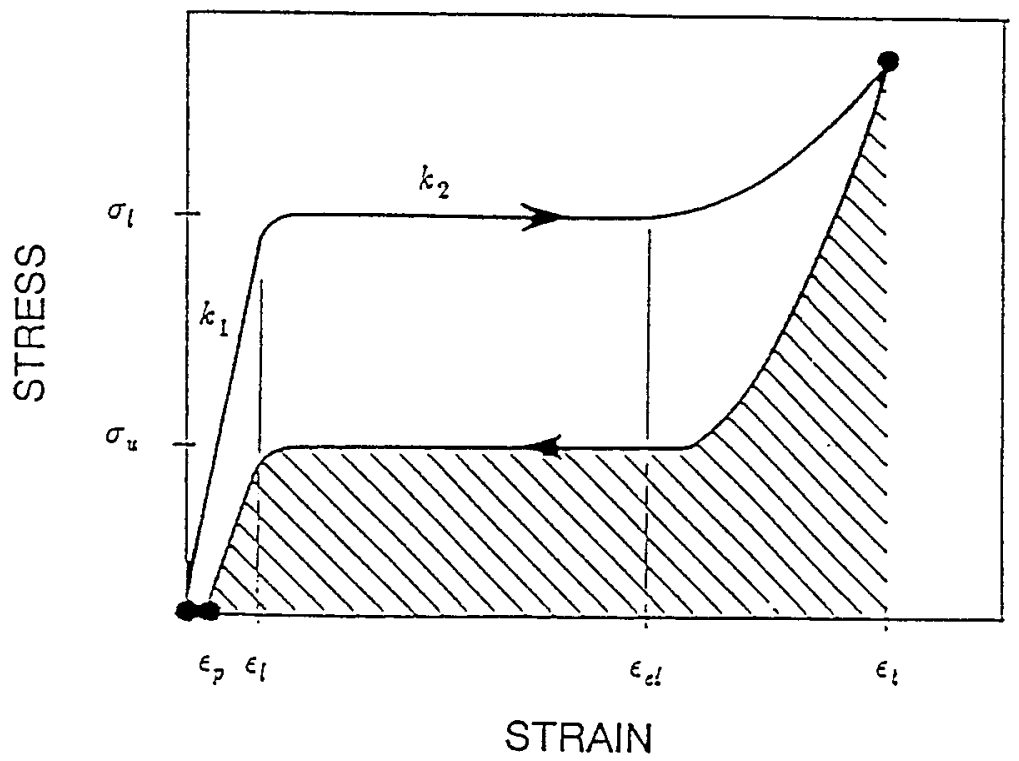

$$
\begin{aligned}
& \varepsilon_{p}=\text { permanent strain } \\
& \varepsilon_{l}=\text { critical loading strain } \\
& \varepsilon_{e l}=\text { elastic limit strain } \\
& \varepsilon_{l}=\text { total strain }
\end{aligned}
$$

$$
\begin{aligned}
& \sigma_{l}=\text { critical loading stress } \\
& \sigma_{u}=\text { critical unloading stress } \\
& k_{1}=\text { initial stiffness } \\
& k_{2}=\text { reduced stiffness }
\end{aligned}
$$

Fig. 34: Superelasticity

The key characteristic is that if the strain is less than $\varepsilon_{e l}$ there is no permanent deformation. In this testing, Nitinol wire was incorporated in series as part of a cross-bracing system in the model. In this configuration, the Nitinol was loaded only in tension, which allowed the full volume of the Nitinol to effectively dissipate energy. A view of the Nitinol cross bracing in the top floor of the model is shown in Fig. 36a, and a close-up view of the Nitinol wire is shown in Fig. 36b.

\section{Summary of Test Results}

The force-deformation behavior of the Nitinol cross bracing that was achieved with no preload in the wire is shown in Fig. 37. Because there was no preload, the wire was able to go slack during compressive portions of the dynamic loading, and as expected, the hysteresis loop shows this behavior for strains up to about 4 percent. One desirable feature of the Nitinol is that its strength increases when $\varepsilon_{e l}$ is exceeded. This means that if the predicted earthquake excitation were to be exceeded, the structure would stiffen rather than soften. When the strain in the material was increased to 8 percent, the hysteretic behavior shown in Fig. 38 was obtained. This loop shows all of the characteristics which are theoretically predicted and were exhibited in the static tests. In these loops there was no preload, and because permanent deformation of the wire occurred during the larger strain cycles the wire was loose at the end of the test. 

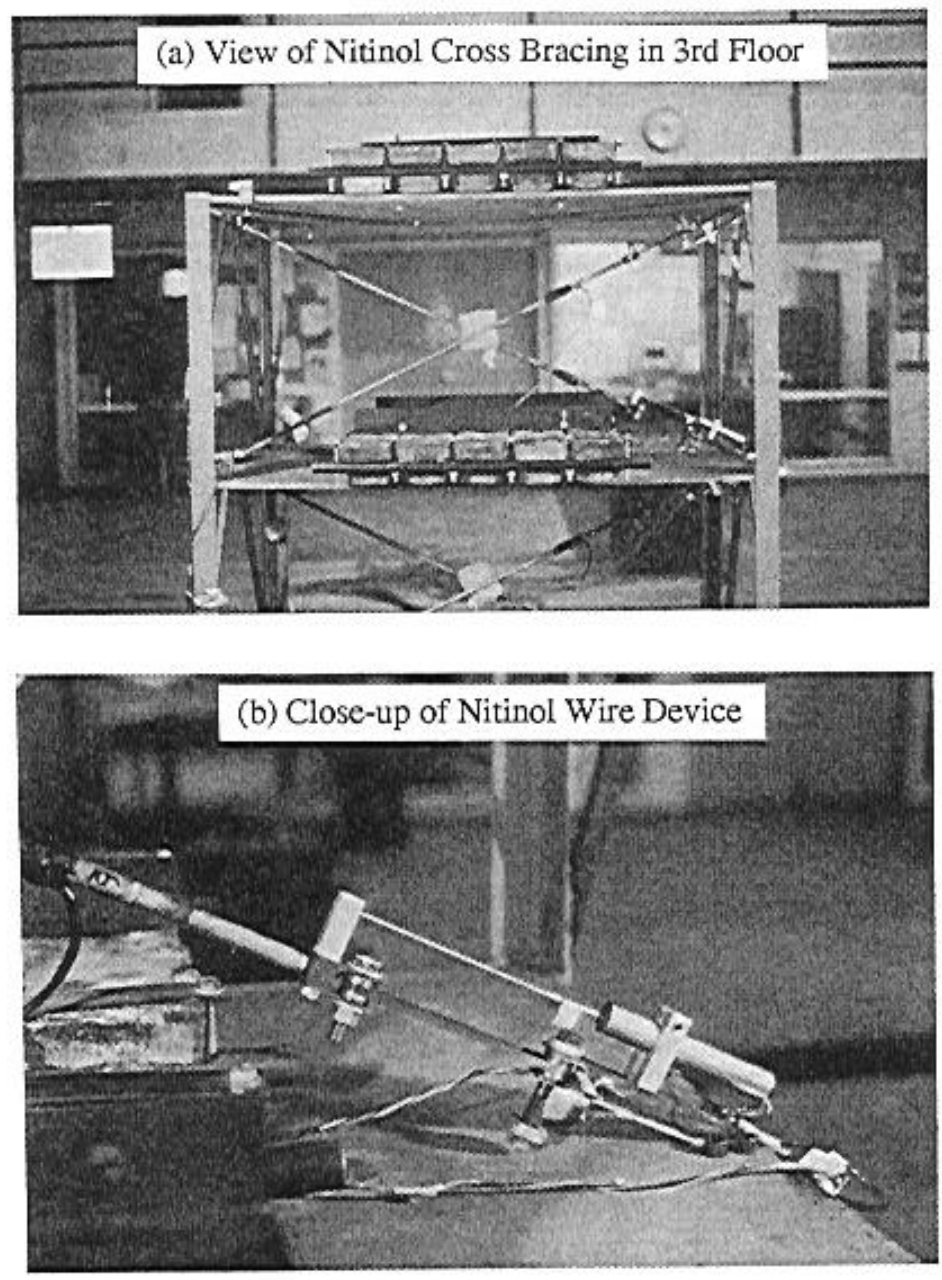

Fig. 35: Installation of Nitinol Wire Device in Model Bracing

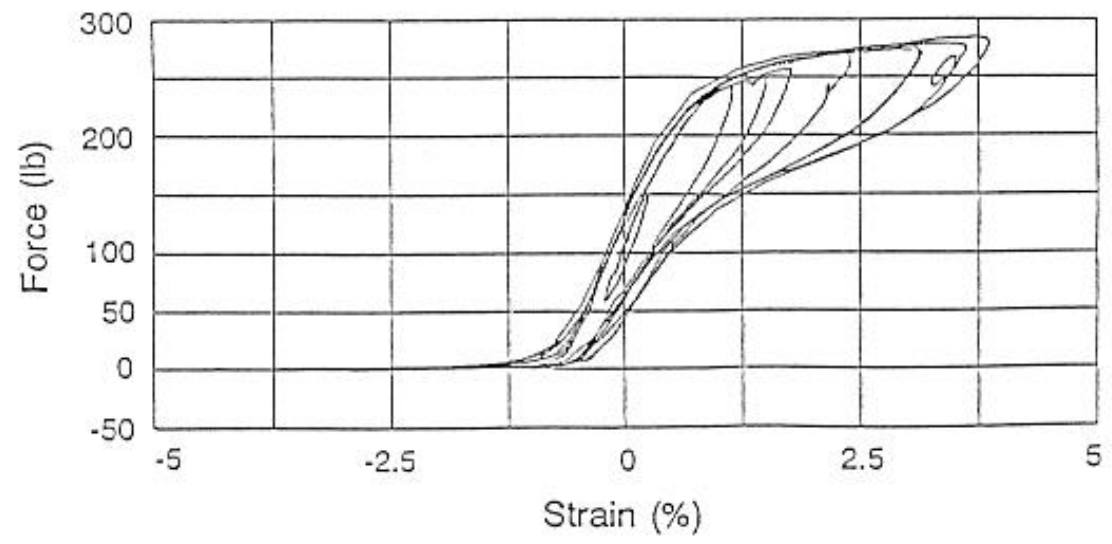

Fig. 36: Nitinol Moderate-Strain Hysteresis Behavior 


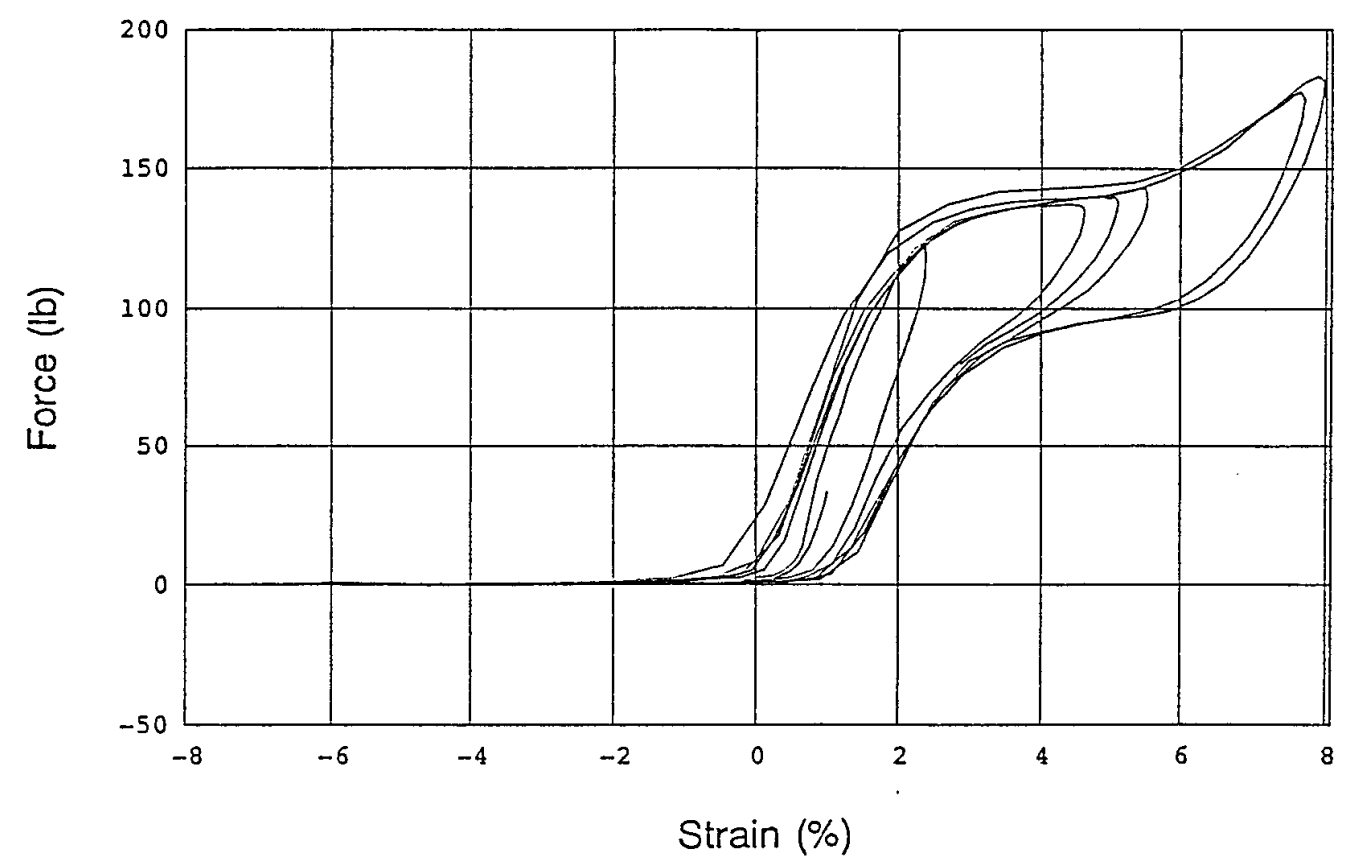

Fig. 37: Nitinol High-Strain Hysteresis Behavior

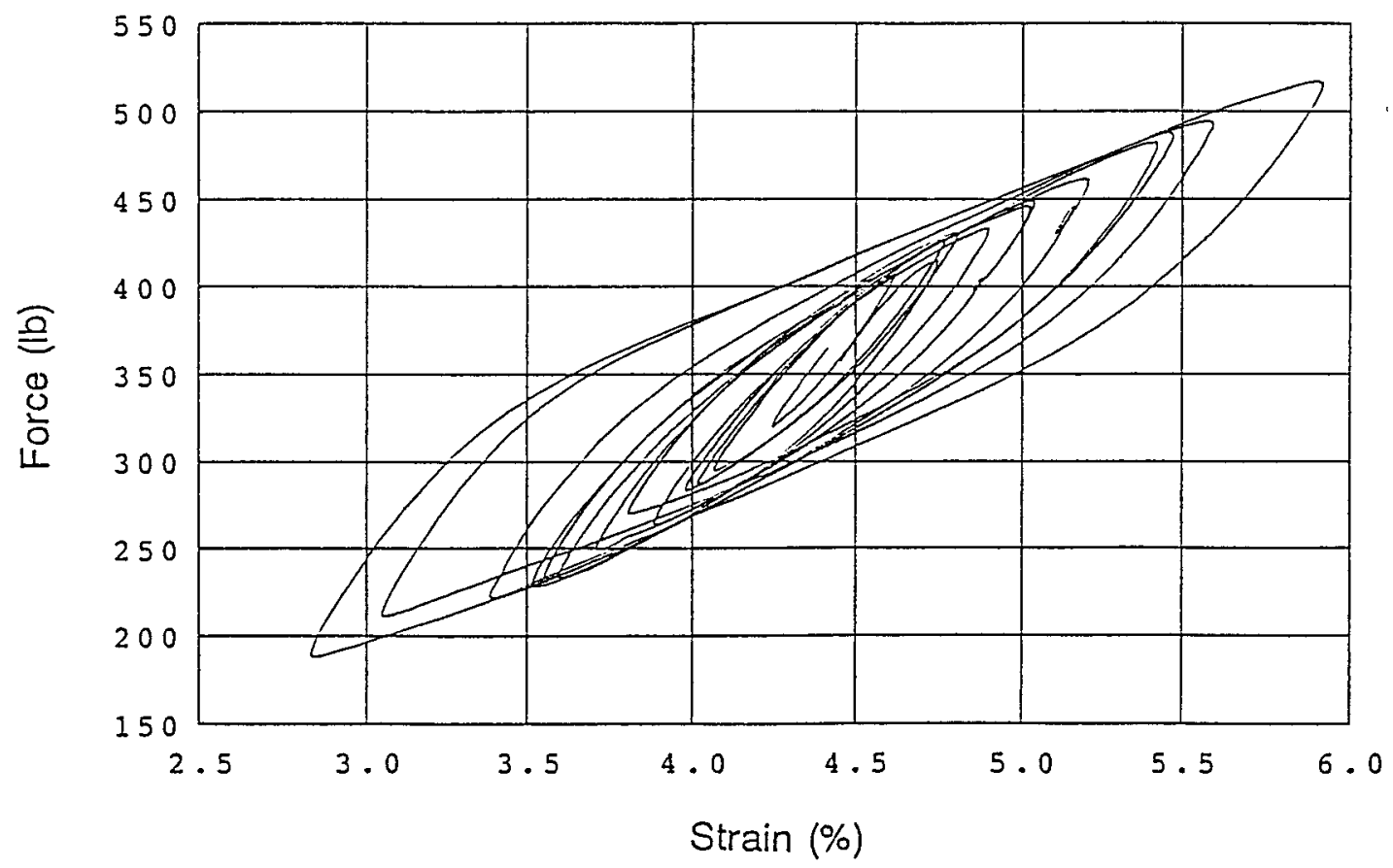

Fig. 38: Nitinol Hysteresis Behavior With Pre-Strain Applied 

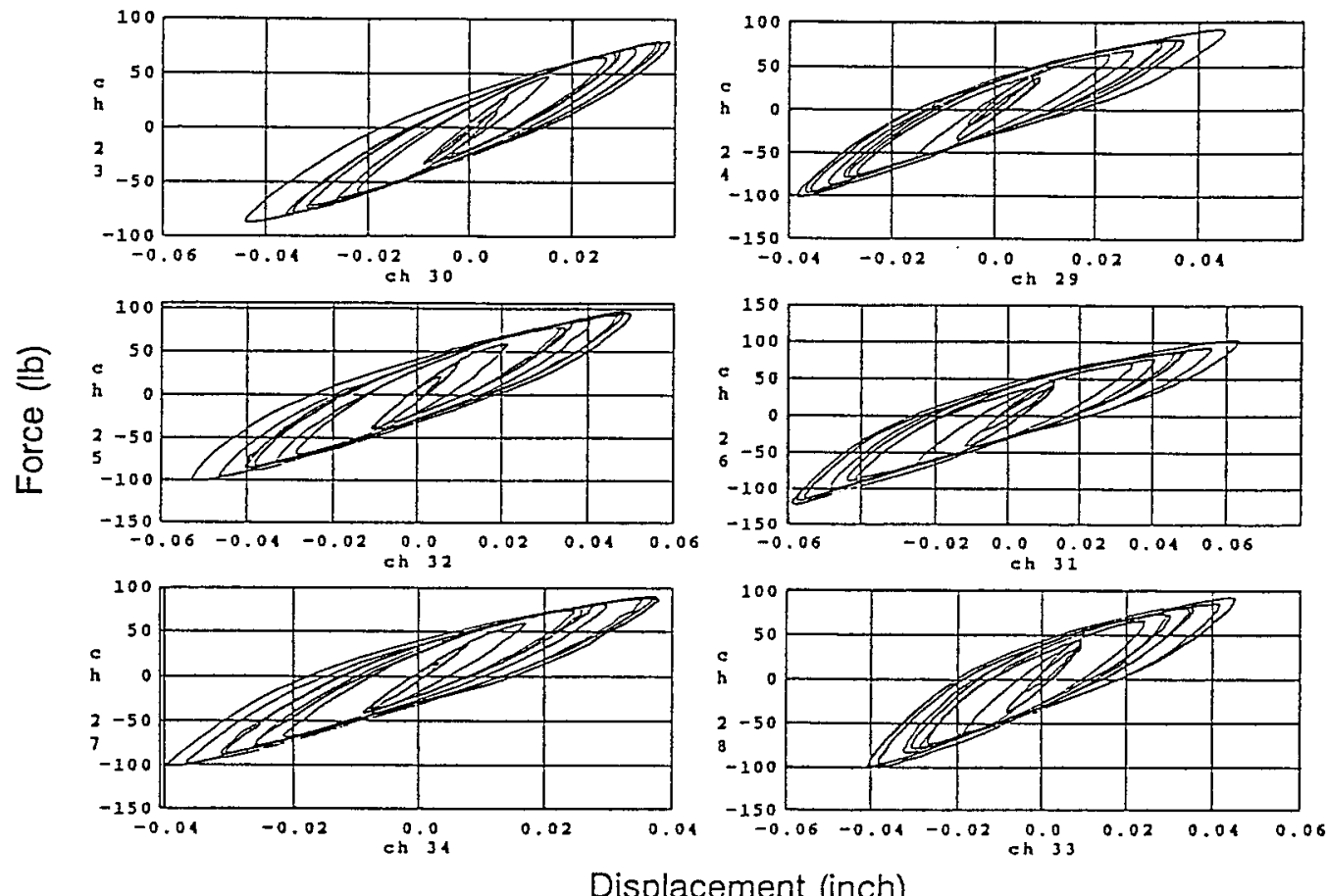

Fig. 39: Hysteresis Loops for All Nitinol Braces From a Typical Test
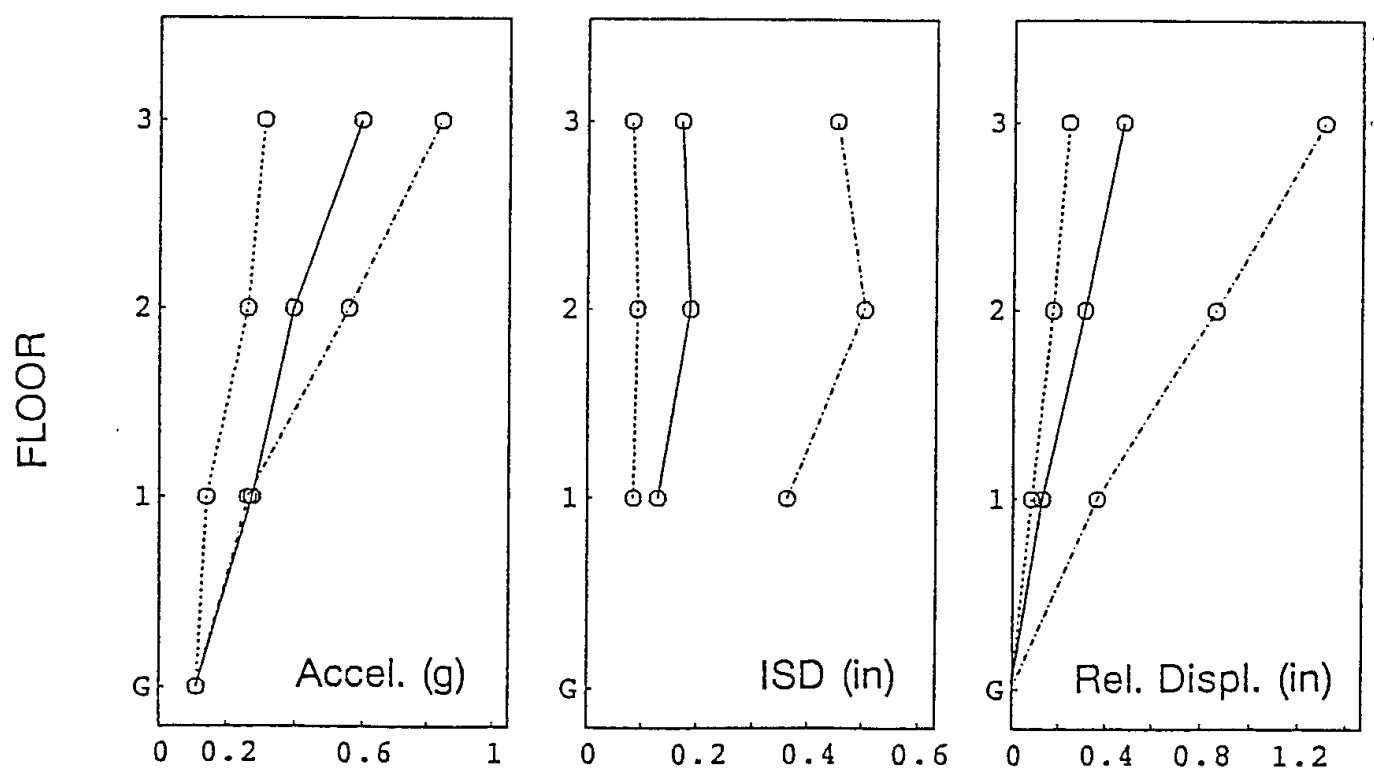

Solid: 20 Strnds Sik Dotted: 20 Strnds Prld Dot-Dash: Bare

Fig. 40: Effect of Nitinol Braces on Response - Zacatula $(\operatorname{span}=100)$ 
With a small preload, it was difficult to achieve uniform behavior in all six braces. To resolve this problem a large preload was applied to the Nitinol (Fig. 39). With the preload applied, the strain in the Nitinol was between 2.5 and 6 percent throughout the testing. Thus, the Nitinol was continuously cycled in the region of hysteresis behavior where the most energy is dissipated. With this loading the Nitinol behaved smoothly in every brace and the behavior was uniform in all of the braces. This is illustrated in Fig. 40, which shows hysteresis loops for both braces in each of the three floors. The loops for all of the floors are similar, and all loops exhibit significant dissipated energy.

The effect of the Nitinol braces on the seismic response of the model under the Zacatula motion is shown in Fig. 41. Results are shown for the bare frame, the frame with the Nitinol allowed to go slack ( 20 strnds slk), and the Nitinol with preload ( 20 strnds prld). The addition of the Nitinol braces significantly reduced the response in both cases. However, the preloaded Nitinol braces caused a greater reduction in all three response parameters. As was found for the EDR, the Nitinol energy dissipator was more effective for the regular Zacatula motion than for the impulsive El Centro motion.

\section{SUMMARY}

The EDR is a friction-based mechanical energy dissipator which has a wide range of possible hysteretic behaviors. The most interesting behavior possesses fat "S-shaped" loops and is selfcentering. In this configuration, the friction force dissipating the energy is proportional to the displacement and the internal preload of the EDR. By its design, the EDR increased both the stiffness and damping of the model. The influence of the added damping was shown to contribute significantly to the reduction in response. One advantage of the EDR is that it can be effective at low levels of seismic excitation or for wind loads while also being effective at high seismic levels. This is because the energy dissipated is proportional to the displacement of the EDR. The testing has established the potential of the EDR as an energy dissipator for building applications.

Nitinol demonstrated the special ability to "yield" repeatedly and not lose its preload. The damping in the structure increased from 0.5 to 3.0 percent, and all of the structural responses were reduced. A Nitinol energy dissipator has the particular advantages of being mechanically very simple and reliable.

\section{CONCLUSIONS}

In a number of different research programs at EERC, at total of seven types of passive energy dissipators have been tested under earthquake shaking conditions in four different model structures.

Large-scale tests of a 9-story steel MRF incorporating two types of friction dampers and one type of viscoelastic damper; tests of a 3-story steel MRF incorporating ADAS elements; tests of a 6-story steel MRF incorporating friction dampers in chevron bracing; and small-scale tests of a 3story steel model incorporating friction dampers and shape-memory alloy dampers, have been performed. The effectiveness of the various types of dampers was evaluated by comparing the response of the structures containing the dampers with the response of the same structures with no dampers or with conventional types of bracing. The benefits of the energy dissipators have been clearly demonstrated by these comparisons, and also by associated analytical studies. The 
improvements in performance have been shown to stem primarily from the increase in energy dissipation available within the structure.

\section{ACKNOWLEDGEMENTS}

Many organizations and individuals contributed to these research studies. Grants from the National Science Foundation and NCEER supported several of the programs. The following companies are recognized for their financial and/or materials support: Bechtel, CounterQuake Corp., Fluor Daniel, Inc., Sumitomo Metal Industries, Ltd. of Tokyo, Japan, and 3M Co. The following individuals are also acknowledged: Darel Hodgson of Shape Memory Applications, Inc., Robert Krumme of E*Sorb Systems, and Dr. A. S. Pall of Pall Dynamics, Ltd., of Montreal, Canada. The opinions expressed in this paper are those of the authors only and do not necessarily reflect the opinions of the sponsors.

\section{REFERENCES}

Aiken, I.D., Kelly., J.M., and Pall, A.S., 1988. "Seismic Response of a Nine-Story Steel Frame with Friction Damped Cross-Bracing," Proc., 9WCEE, Tokyo/Kyoto, Japan.

Aiken, I.D., Kelly., J.M., and Mahmoodi, P., 1990a. "The Application of Viscoelastic Dampers to Seismically Resistant Structures," Proc., 4USNCEE, Palm Springs, Calif.

Aiken, I.D., and Kelly, J.M., 1990b. "Earthquake Simulator Testing and Analytical Studies of Two Energy-Absorbing Systems for Multistory Structures," Report UCB/EERC-90/03, Earthquake Eng. Res. Ctr, Univ. of California, Berkeley.

Aiken, I.D., Nims, D.K., and Kelly, J.M., 1992. "Comparative Study of Four Passive Energy Dissipation Systems,” Bull. N.Z. Nat. Soc. for Earthquake Eng., Vol. 25, No. 3.

Bergman, D.M., and Goel, S.C., 1987. "Evaluation of Cyclic Testing of Steel-Plate Devices for Added Damping and Stiffness," Report UMCE 87-10, Dept. of Civil Eng., Univ. of Michigan, Ann Arbor.

Boardman, P.R., Wood. B.J., and Carr, A.J., 1983. "Union House - A Cross Braced Structure With Energy Dissipators," Bull. N.Z. Nat. Soc. for Earthquake Eng., Vol. 16, No. 2.

Fiero, E., Perry, C., Sedarat, H., and Scholl, R., 1993. "Seismic Retrofit in San Francisco Using Energy Dissipation Devices," submitted to Earthquake Spectra, Special Issue, Vol. 9, No. 3, EERI.

Filiatrault, A., and Cherry, S., 1990a. "Seismic Design Spectra for Friction Damped Structures," Jnl of the Str. Div., Vol. 116, No. ST5, ASCE, New York.

Filiatrault, A., and Cherry, S., 1990b. “A Simplified Seismic Design Procedure for Friction Damped Structures," Proc., 4USNCEE, Palm Springs, Calif.

Giacchetti, R., Whittaker, A.S., Bertero, V.V., and Aktan, H.M., 1989. "Seismic Response of A DMRSF Retrofitted With Friction Slip Devices," Proc., First Int. Meeting on Base Isolation and Passive Energy Dissipation, Assisi, Italy. 
Graesser, E.J., and Cozzarelli, F.A., 1991. "Shape Memory Alloys as New Materials for Aseismic Isolation," Jnl of Eng. Mechs., Vol. 117, No. 11, ASCE, New York.

Hodgson, D.E., 1988. “Using Shape Memory Alloys,” Shape Memory Applications, Inc., Sunnyvale, Calif.

Keel, C.J., and Mahmoodi, P., 1986. "Design of Viscoelastic Dampers for the Columbia Center Building," Building Motion in Wind, ASCE, New York.

Kelly, J.M., Skinner, R.I., and Heine, A.J., 1972. "Mechanisms of Energy Absorption in Special Devices for Use in Earthquake-Resistant Structures,” Bull. N.Z. Nat. Soc. for Earthquake Eng., Vol. 5, No. 3.

Kelly, J.M., and Skinner, M.S., 1980. “Development and Testing of Restraints for Nuclear Piping Systems," Report UCB/EERC-80/21, Earthquake Eng. Res. Ctr, Univ. of California, Berkeley.

Lin, R.C., Liang, Z., Soong, T.T., and Zhang, R.H., 1988. “An Experimental Study of Seismic Structural Response With Added Viscoelastic Dampers,” Report NCEER-88-0018, NCEER, State Univ. of New York at Buffalo.

Mahmoodi, P., 1969. “Structural Dampers," Jnl of the Str. Div., Vol. 95, No. ST8, ASCE, New York.

Mahmoodi, P., Robertson, L.E., Yontar, M., Moy, C., and Feld, L., 1987. "Performance of Viscoelastic Dampers in World Trade Center Towers," Proc., 5th ASCE Strs. Cong., Orlando, Florida.

Mahmoodi, P., and Keel, C.J., 1989. "Analysis and Design of Multi-Layer Viscoelastic Dampers for Tall Structures," Proc., 7th ASCE Strs. Cong., San Francisco, Calif.

Nims, D.K., Richter, P.J., and Bachman, R.E., 1993. "The Use of the Energy Dissipating Restraint for Seismic Hazard Mitigation," submitted to Earthquake Spectra, Special Issue, Vol. 9, No. 3, EERI.

Pall,A.S., and Marsh, C., 1982. "Seismic Response of Friction Damped Braced Frames," Jnl of the Str. Div., Vol. 108, No. ST6, ASCE, New York.

Pall,A.S., Verganelakis, V., and Marsh, C., 1987. "Friction Dampers for Seismic Control of Concordia Library Building," Proc., 5th Canadian Conf. on Earthquake Eng., Ottawa, Canada.

Pall,A.S., Ghorayeb, F., and Pall, R., 1991. "Friction-Dampers for Rehabilitation of Ecole Polyvalente at Sorel, Quebec," Proc., 6th Canadian Conf. on Earthquake Eng., Toronto, Canada.

Richter, P.J., Nims, D.K., Kelly, J.M., and Kallenback, R.M., 1990. “The EDR-Energy Dissipating Restraint, A New Device for Mitigating Seismic Effects," Proc., SEAOC Ann. Conv., SEAOC, Lake Tahoe.

Sasaki, K., 1989. “Experimental Evaluation of Nitinol for Energy Dissipating Devices,” Report UCB/SEMM-89/20, Dept. of Civil Eng., Univ. of California, Berkeley. 
Steimer, S.F., and Godden, W.G., 1980. "Shaking Table Tests of Piping Systems With EnergyAbsorbing Restrainers," Report UCB/EERC-80/33, Earthquake Eng. Res. Ctr, Univ. of California, Berkeley.

Steimer, S.F., Godden, W.G., and Kelly, J.M., 1981. "Experimental Behavior of a Spatial Piping System With Steel Energy Absorbers Subjected to a Simulated Differential Seismic Input," Report UCB/EERC-81/09, Earthquake Eng. Res. Ctr, Univ. of California, Berkeley.

Steimer, S.F., and Chow, F.L., 1984. "Curved Plate Energy Absorbers for Earthquake Resistant Structures," Proc., 8WCEE, San Francisco, Calif.

Tyler, R.G., 1978. “Tapered Steel Cantilever Energy Absorbers,” Bull. N.Z. Nat. Soc. for Earthquake Eng., Vol. 11, No. 4.

Tyler, R.G., 1983. "Preliminary Tests on an Energy Absorbing Element for Braced Structures Under Earthquake Loading," Bull. N.Z. Nat. Soc. for Earthquake Eng., Vol. 16, No. 3.

Uang, C.-M. and Bertero, V.V., 1988. "Use of Energy as a Design Criterion in Earthquake Resistant Design," Report UCB/EERC-88/18, Earthquake Eng. Res. Ctr, Univ. of California, Berkeley.

Vezina, S., Proulx, P., Pall, R., and Pall, A.S., 1992. "Friction-Dampers for Aseismic Design of Canadian Space Agency," Proc., 10WCEE, Madrid, Spain.

Whittaker, A.S., Uang, C.-M., and Bertero, V.V., 1990. "An Experimental Study of the Behavior of Dual Steel Systems," Report UCB/EERC-88/14, Earthquake Eng. Res. Ctr, Univ. of California, Berkeley.

Whittaker, A.S., Bertero, V.V., Thompson, C.L., and Alonso, L.J., 1991. "Seismic Testing of Steel Plate Energy Dissipation Devices,” Earthquake Spectra, Vol. 7, No. 4, EERI.

Witting, P.R., and Cozzarelli, F.A, 1992. "Shape Memory Structural Dampers: Material Properties, Design and Seismic Testing," Report NCEER-92-0013, NCEER, State Univ. of New York at Buffalo.

Yokota, H., Saruta, M., Nakamura., Y., Satake, N., and Okada, K., 1992. "Structural Control for Seismic Load Using Viscoelastic Dampers," Proc., 10WCEE, Madrid, Spain.

Zhang, R.H., Soong, T.T., and Mahmoodi, P., 1989. "Seismic Response of Steel Frame Structures With Added Viscoelastic Dampers, Earthquake Eng. \& Str. Dyn., Vol. 18, No. 3. 